Article

\title{
Air Quality in Lombardy, Italy: An Overview of the Environmental Monitoring System of ARPA Lombardia
}

\author{
Paolo Maranzano (D)
}

check for

updates

Citation: Maranzano, P. Air Quality in Lombardy, Italy: An Overview of the Environmental Monitoring System of ARPA Lombardia. Earth 2022, 3, 172-203. https://doi.org/ $10.3390 /$ earth 3010013

Academic Editor: Carmine Serio

Received: 17 December 2021

Accepted: 31 January 2022

Published: 7 February 2022

Publisher's Note: MDPI stays neutral with regard to jurisdictional claims in published maps and institutional affiliations.

Copyright: (C) 2022 by the author. Licensee MDPI, Basel, Switzerland. This article is an open access article distributed under the terms and conditions of the Creative Commons Attribution (CC BY) license (https:// creativecommons.org/licenses/by/ $4.0 /)$.
Department of Economics, Management and Statistics (DEMS), University of Milano-Bicocca, Piazza dell'Ateneo Nuovo, 1, 20126 Milano, Italy; paolo.maranzano@unibg.it

\begin{abstract}
In this paper, we describe the structure and the features of the air quality and meteorological monitoring system adopted in the Lombardy region in Northern Italy. We are interested in describing which data the Regional Agency for Environmental Protection (ARPA Lombardia) must collect, how this process takes place and how they are disseminated to the public for institutional communication and research purposes. ARPA monitors the atmospheric conditions through a dense ground monitoring network composed mainly by permanent stations, but also by mobile samplers. We describe in a detailed fashion the structure of the network: how many stations the network consists of, their locations, which pollutants and weather events are monitored and with what frequency. Our main objective is to present to an international audience the case study of ARPA Lombardia and the main available public data, explicitly stating the sources of information and how to find them, and encouraging international researchers to deal with the subject. In spite of the significant and extensive efforts made to counteract the phenomenon of air pollution, the air quality recorded in the region is very poor, and the local authorities are struggling to comply with international regulations on the concentration of pollutants in the air, making Lombardy a relevant international case. In addition, we present in a synthetic and descriptive way, without any modeling ambition, some data observed in the last years in Lombardy regarding meteorology and the main pollutants (oxides and particulate matters). The empirical descriptive results have been obtained by analyzing sample data provided by ARPA Lombardia through the same sources described in the sections dedicated to the Agency. From the graphical analysis, it is noticeable that at aggregate (regional) level, the concentrations are affected by significant decreasing trends, but at a rather contained speed. This is particularly true for the concentrations of oxides $\left(\mathrm{NO}_{2}\right.$ and $\left.\mathrm{NO}_{X}\right)$ in urban and industrial areas. However, particulate matters and ozone show a high persistence in the average concentrations, interrupted only by the alternation of climatic seasons. The data also show that the meteorology of the region does not seem favorable for the improvement of air quality, as the region is characterized by low precipitation, and wind almost everywhere is not very intense. This situation could be induced by the unfavorable geography of the area, which prevents adequate air recycling and facilitates the stagnation of pollutants. We suggest that any public policy intervention aimed at improving the air quality situation in the region should take into account this empirical evidence in the impact assessment phase.
\end{abstract}

Keywords: ARPA Lombardia; Northern Italy; air quality and meteorology; environmental ground monitoring network; airborne pollutants

\section{Rationale and Background}

As reported by the UN Environmental Outlook 2019 [1], environmental governance, and in particular air quality management, is increasingly important at all levels, including national and regional governments, as well as business and civil society stakeholders. Several definitions of air quality management have been proposed: an effective and efficient tool employed in managing acceptable air quality [2] and a set of actions that helps in attaining air quality goals in a specified geographical area, and it requires actions by government, business, industry and population [3]. 
To face the issue of air quality management, countries worldwide have adopted organizations and institutions at supra-national, national and local levels for air quality monitoring and analysis, environmental protection and planning of public policies toward sustainable development. As defined in all European directives on air quality, it is very important to guarantee the production and collection of data with standardized and common measurement criteria. These guarantee a mutual exchange of information collected, such as to make the phenomenon more and more representative and comparable throughout the community. They improve the understanding of the phenomenon and its impacts, and allow the development of more and more appropriate policies.

There is a need for greater synergies between governments and civil society organizations. Many efforts have been made to develop more effective facilitation methods to enable this collaboration, first, by extending the Citizen science philosophy [4], which pushes toward more effective collaboration between public institutions, research, and active citizenship, and engaging citizens in scientific research to help address some of the most pressing issues in ecology, such as global environmental change. In the field of air quality research, citizen science can be a useful approach to collect specific data or model special observed situations, acting as a producer of "big data" for spatial ecology. For example, air pollution does not necessarily spread evenly across an area. People may live next to a busy highway or some other source of pollution, or live in areas with terrain topography that generates pockets of air pollutants not identified by aggregate analysis. Citizen scientists can contribute more information to fill natural gaps in the databases of official statistics.

This manuscript attempts to contribute to the Citizen science philosophy by providing a robust overview of European and Italian air quality monitoring systems, and focusing on the particular case of the Lombardy region (Northern Italy). The Lombardy case will be discussed in the light of its main geographical and physical characteristics, the composition of the economic and social network and the consequent effects on air pollution. We present and describe air quality and weather measurements provided by the Regional Agency for Environmental Protection, namely ARPA Lombardia, which manages and maintains the monitoring network and analyzes the collected data. ARPA monitors the atmosphere through a dense ground monitoring network composed mainly by permanent stations, but also by mobile samplers.

Our main objective is to present to an international audience the case study of ARPA Lombardia. Following other recent studies, such as the one by [5] for the case of ARPA Puglia, we present the role, the structure and the duties of ARPA Lombardia in light of the Italian and European Legislation on air quality monitoring. In particular, we present the composition of the network, i.e., which pollutants and weather events are monitored, the sampling frequency and the spatial resolution of the data, and we depict the data collection mechanism adopted by the Agency, including the quality checks the agency operates on the data to ensure that measurements are as reliable as possible before being released to the public. Additionally, we describe the available public data on air quality for Lombardy, explicitly stating the sources of information and how to find them, and how the agency disseminates the information for institutional communication and research purposes.

One of the core contributions of the paper is to offer to the readers the necessary guidance to retrieve data and metadata of the case of interest. In the literature, it is possible to find many studies that go in similar directions and that present databases or portals for the extraction of public environmental data, see for example [6] for the MISTRAL project (Meteo Italian SupercompuTing PoRtAl) or [7] for the PRISMA project (Italian network for meteors and atmospheric studies). Compared to this kind of papers, this essay additionally presents some empirical evidence concerning air quality and meteorology in Lombardy using these same public data provided by ARPA Agency.

The remainder of the paper is structured as follows. In Section 2, we discuss some of the most relevant issues raised in the literature on the use of data from institutional monitoring networks in analysis. In particular, we address the problem of redundancy and the emerging market for low-cost sensors. In Section 3, we describe the current 
European legislation on air quality monitoring and health protection show some empirical evidence about the trends of airborne pollutant emissions and their anthropogenic sources. Particularly, we provide some insights on the current trends of air quality across Europe, focusing on nitrogen oxides $\left(\mathrm{NO}_{X}\right.$ and $\left.\mathrm{NO}_{2}\right)$ and particulate matters $\left(\mathrm{PM}_{10}\right.$ and $\left.\mathrm{PM}_{2.5}\right)$ dynamics. In Section 4 , we present the Italian air quality monitoring system (SNPA) and its relation with the European system called EIONet. Additionally, we discuss in rigorous detail the case of the Regional Environmental Protection Agency for Lombardy, namely ARPA Lombardia, describing how its network is structured, what data it collects, the quality of the data and how it disseminates them to the public. In Section 5, using the data collected through the open database of ARPA Lombardia, we provide empirical evidence about air quality and meteorology conditions observed in Lombardy in the last years (from 2014 to 2020), attempting to relate it to the international indications on atmospheric concentrations. Finally, in Section 6, we summarize the evidence and conclude the paper.

\section{Issues Concerning Air Quality Monitoring Networks}

The use of air quality data from local or regional monitoring networks is a longstanding practice in the literature [8-11,51]. The quality of sampling instrumentation and the design of the air quality monitoring network must comply with international standards and are guaranteed by the institutions responsible for their management. However, the measurements and the associated metadata for each site depend on the institution in charge of the air quality monitoring, which work using specific criteria that can be sometimes rather subjective, hence can heavily differ from a country to another [12].

Focusing on the Italian case, there are a number of studies investigating the characteristics of air quality and the relation with local meteorology, but presenting the existing monitoring networks and data sources in a rapid way. See, for example, the studies by [13,14] for air quality in Piedmont, [15] for Veneto, the study of [16] for Emilia-Romagna, and [17] for the port area in Salerno (Southern Italy). In all cases, these are empirical studies in which the focus is the application of statistical methodologies for air quality analysis and in which the structure of the monitoring networks is of minor interest.

A relevant issue concerning ground monitoring networks is the existence of redundant monitoring stations, which results in a significant increase in monitoring costs and can negatively affect the accuracy of air quality assessment. There are several examples of identifying the optimal location (optimal design) of monitoring stations using spatial correlation techniques [18], optimization algorithm [19] and dimensionality reduction [20]. From the findings, it is generally verified that the networks are redundant and the number of stations can be reduced without loss of informativeness.

The literature is also exploring the integration of institutional monitoring networks with informal networks of air pollution platforms consisting of low-cost, easy-to-use, and very compact sensors [21]. Informal sensors are often used in monitoring indoor air quality [22]. See the review article [23] for an updated state-of-art of the current literature on low-cost sensors technology. Such instrumentation allows for high spatial resolution observations in near real time and provides new opportunities to simultaneously improve existing monitoring systems and engage citizens in active environmental monitoring [24]. Of course, the emergence of this integration also raises the issue of data validation and instrument calibration [25]. Data from low-cost sensors depend on the conditions of the surrounding space (atmospheric composition and meteorological conditions), leading to high variability in performance and reducing its quality. Hence the need to develop appropriate data validation techniques, identification of outliers and failures [26,27].

\section{European Air Quality Standards and Current Trends of Pollutant Emissions}

Airborne pollutants have very different origins and derive from many sources of anthropogenic emissions. Table 1 describes the principal airborne pollutants monitored by the European agencies, along with a list of their emission sources. Pollutants are also classified as primary substances, i.e., released into the atmosphere directly from sources, 
whether anthropogenic or natural, or secondary pollutant, i.e., formed in the atmosphere subsequently due to chemical or physical reactions involving other species of pollutants.

Table 1. Main emission sources by type of pollutant.

\begin{tabular}{ccl}
\hline Pollutant & Classification & $\begin{array}{l}\text { Anthropogenic Sources } \\
\mathrm{PM}_{10}\end{array}$ \\
$\mathrm{PM}_{2.5}$ & Both & $\begin{array}{l}\text { Combustion and mechanical actions (erosion, friction, etc.), } \\
\text { chemical-physical processes that occur in the atmosphere } \\
\text { starting from precursors even in the gaseous phase. }\end{array}$ \\
$\mathrm{O}_{3}$ & Secondary & $\begin{array}{l}\text { There are no significant anthropogenic emission sources } \\
\text { into the atmosphere. }\end{array}$ \\
$\mathrm{NO}_{2}$ & Both & $\begin{array}{l}\text { Heating systems, motor vehicle traffic, power plants, } \\
\text { industrial activities (combustion processes). } \\
\text { Road traffic. }\end{array}$ \\
$\mathrm{SO}_{2}$ & Primary & $\begin{array}{l}\text { Heating systems, power plants, combustion of organic } \\
\text { products of fossil origin containing sulfur (diesel, coal, fuel oils). }\end{array}$ \\
\hline
\end{tabular}

As the main legal instrument for air quality monitoring and guiding countries' behavior towards environmental protection, international institutions have established some quantitative limits on pollutant concentrations. The limits in force on the European territory have been formalized by the European Union through two EU Ambient Air Quality Directives [28,29] and by the World Health Organization through the air quality guidelines [30,31]. In particular, the 50/2008 European Air Quality Directive (AQD) [29] requires EU Member States to design appropriate air quality plans for zones where the air quality does not comply with the AQD limit values. The EU limits for the main airborne pollutant are here reported in Table 2.

Table 2. Air quality standards given in the EU Ambient Air Quality Directives.

\begin{tabular}{cccc}
\hline Pollutant & Averaging Period & Limit Value & Comments \\
\hline $\mathrm{PM}_{10}$ & $\begin{array}{c}\text { daily mean } \\
\text { yearly mean }\end{array}$ & $\begin{array}{c}50 \mu \mathrm{g} / \mathrm{m}^{3} \\
40 \mu \mathrm{g} / \mathrm{m}^{3}\end{array}$ & $\begin{array}{c}\text { Not to be exceeded on more than } \\
\text { 35 days per year }\end{array}$ \\
\hline $\mathrm{PM}_{2.5}$ & yearly mean & $25 \mu \mathrm{g} / \mathrm{m}^{3}$ & $\begin{array}{c}\text { Maximum exposure } \\
\text { concentration } 20 \mu \mathrm{g} / \mathrm{m}^{3}\end{array}$ \\
\hline $\mathrm{O}_{3}$ & $\begin{array}{c}\text { max daily 8-h mean } \\
\text { hourly mean }\end{array}$ & $120 \mu \mathrm{g} / \mathrm{m}^{3}$ & $\begin{array}{c}\text { Not to be exceeded on more than } \\
\text { 25 times per year }\end{array}$ \\
\hline $\mathrm{NO}_{2}$ & $\begin{array}{c}\text { hourly mean } \\
\text { yearly mean }\end{array}$ & $\begin{array}{c}200 \mu \mathrm{g} / \mathrm{m}^{3} \\
40 \mu \mathrm{g} / \mathrm{m}^{3}\end{array}$ & $\begin{array}{c}\text { Not to be exceeded on more than } \\
18 \text { times per year }\end{array}$ \\
\hline \multirow{2}{*}{$\mathrm{SO}_{2}$} & $\begin{array}{c}\text { hourly mean } \\
\text { daily mean }\end{array}$ & $\begin{array}{c}350 \mu \mathrm{g} / \mathrm{m}^{3} \\
125 \mu \mathrm{g} / \mathrm{m}^{3}\end{array}$ & $\begin{array}{c}\text { Not to be exceeded on more than } \\
\text { 24 times per year (hourly) } \\
\text { and 3 times per year (daily) }\end{array}$ \\
\hline $\mathrm{CO}^{*}$ & max daily 8-h mean & $10 \mathrm{mg} / \mathrm{m}^{3}$ &
\end{tabular}

Source: Air Quality in Europe 2019, EEA report. Note on exposure to $\mathrm{PM}_{2.5}$ : the values are determined at national level and are based on the average exposure indicator (AEI). The exposure is determined as a 3-year running annual mean $\mathrm{PM}_{2.5}$ concentration averaged over selected monitoring stations in urban background locations to best assess the $\mathrm{PM}_{2.5}$ exposure of the general population.

The air quality situation for Europe is constantly updated by the European Environmental Agency (EEA), which presents a yearly report reviewing the progress made towards meeting the air quality standards established in the EU Ambient Air Quality Directives and towards the World Health Organization (WHO) air quality guidelines (AQGs). The report also assesses progress towards the long-term objectives of achieving air pollution levels that do not lead to unacceptable harm to human health and the environment, as presented in the $[32,33]$ environment action programs. 
Over the past decade, air quality has slowly improved in many of Europe's cities due to more robust air quality policies across various governance levels, the introduction of targeted measures and actions, and technological improvements that have reduced emissions from various sources. These reductions were achieved through various means, including implementing regulations, non-regulatory instruments, and technological improvements for transportation vehicles and industrial processes. The adoption of more environmentally sustainable practices by consumers and industry, such as using public transit and carpooling, and optimizing production processes to reduce energy use, have also contributed to the decrease. Figure 1 shows the temporal evolution of the main macro-pollutants within EEA country members and clearly states the decreasing trends for all of them. Extreme are the reductions associated with sulfur dioxide $\left(\mathrm{SO}_{2}\right)$ and nitrogen oxides $\left(\mathrm{NO}_{X}\right)$, which halve emissions compared to 1990.

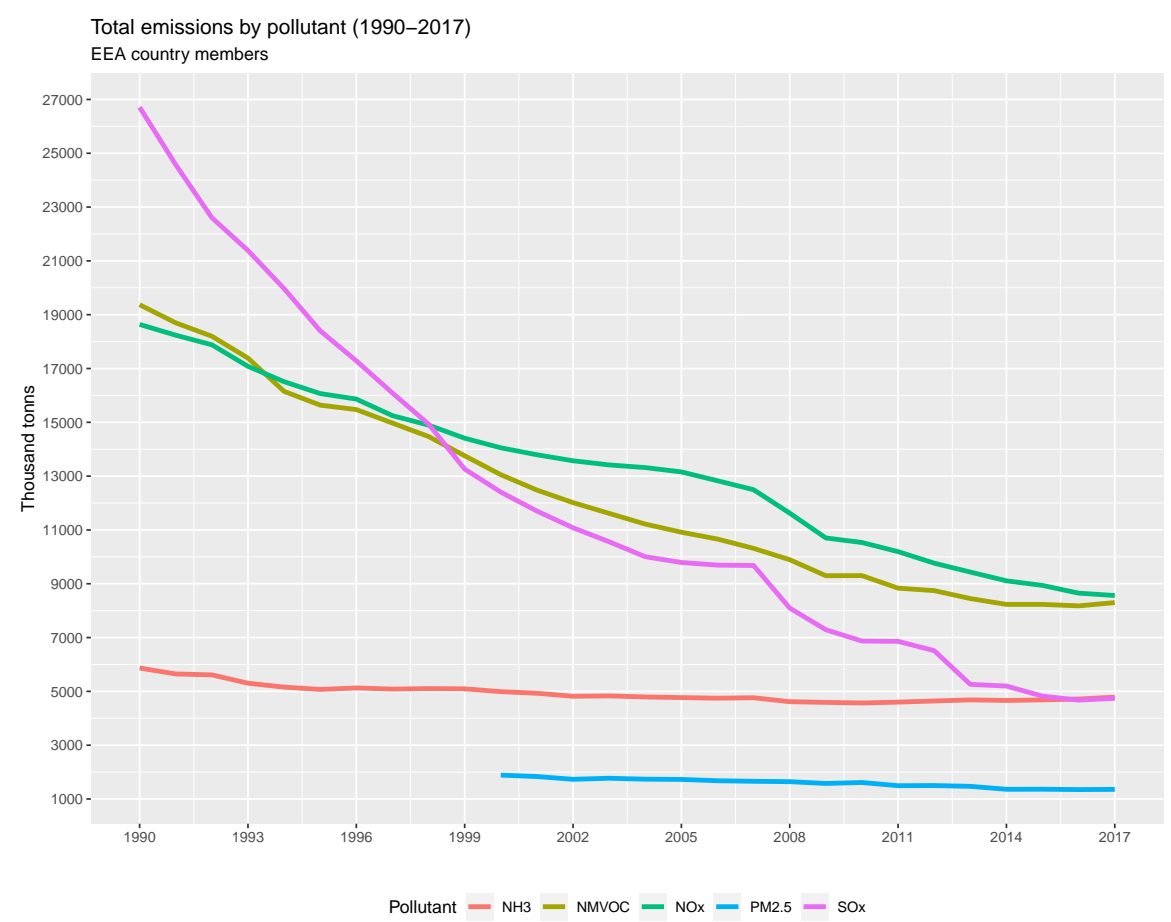

Figure 1. Total emissions in EEA country members since 1990. Source: EEA website.

As shown in Figure 2, the air of European cities is strongly negatively affected by road traffic emissions and industrial production processes. These sectors significantly influence $\mathrm{CO}$, particulate matters, and oxides emissions, accounting for more than half of total emissions.

Nevertheless, many cities and regions still experience excesses of the regulated limits for air pollutants [34]. According to the EEA Air Quality Report 2019 [35] in 2017, around $7 \%$ of the EU-28 urban population was exposed to concentrations above the annual EU limit value for $\mathrm{NO}_{2}$. This fact is a successful milestone and represents the lowest value since 2000. Table 3 reports the EU reference concentrations and the percentage of the urban population in the EU-28 exposed to air pollutant concentrations in 2015-2017 by type of air pollutant. 


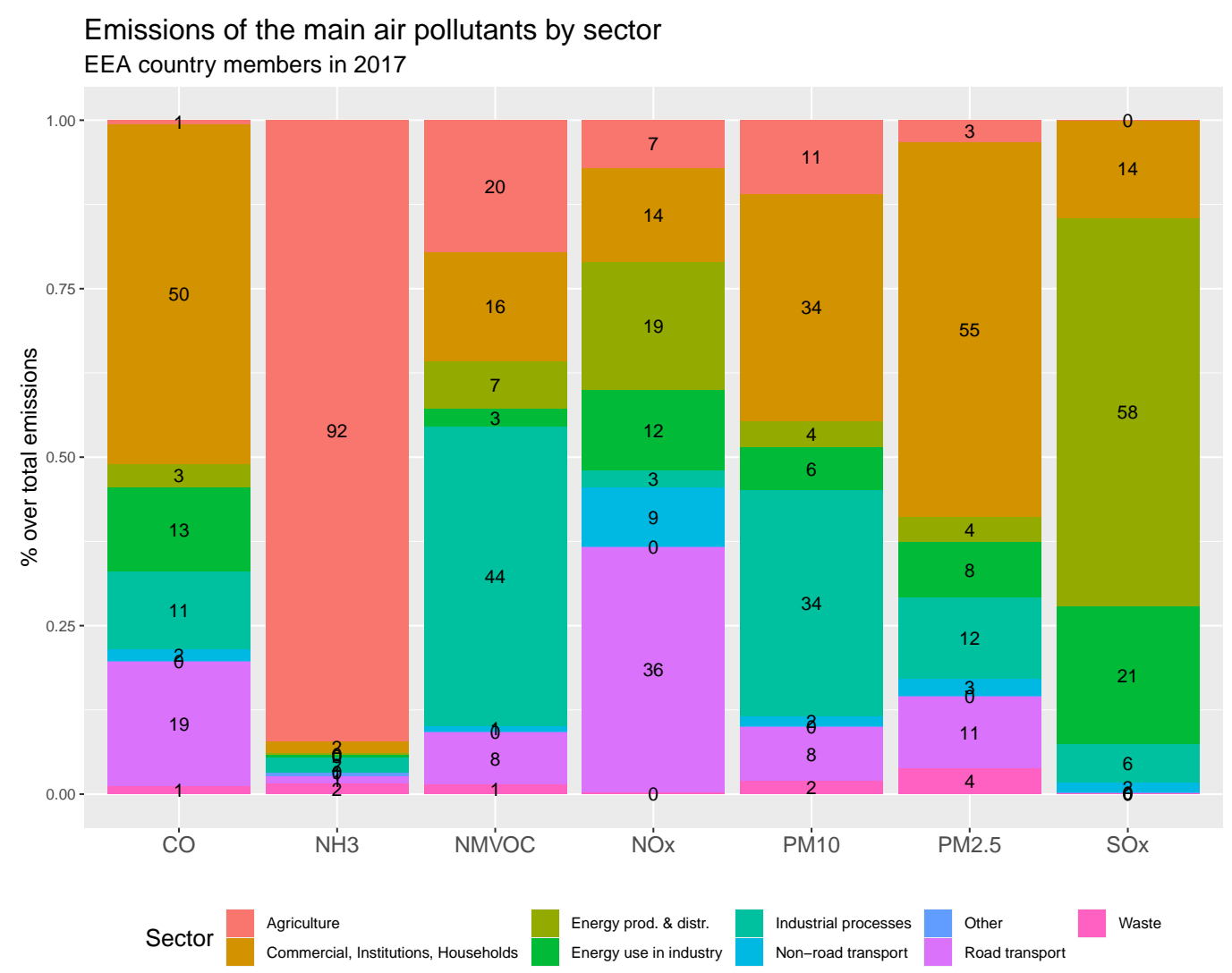

Figure 2. Distribution of total emissions by sectors in EEA country members in 2017. Source: EEA website.

Table 3. Percentage of the urban population in the EU-28 exposed to air pollutant concentrations above EU reference concentrations (minimum and maximum observed between 2015 and 2017).

\begin{tabular}{ccc}
\hline Pollutant & EU Reference Value & Urban Population Exposure \\
\hline $\mathrm{PM}_{10}$ & $50 \mu \mathrm{g} / \mathrm{m}^{3}$ per day & $13-19 \%$ \\
$\mathrm{PM}_{2.5}$ & $25 \mu \mathrm{g} / \mathrm{m}^{3}$ per day & $6-8 \%$ \\
$\mathrm{O}_{3}$ & $120 \mu \mathrm{g} / \mathrm{m}^{3}$ each $8 \mathrm{~h}$ & $12-29 \%$ \\
$\mathrm{NO}_{2}$ & $40 \mu \mathrm{g} / \mathrm{m}^{3}$ per year & $7-8 \%$ \\
\hline
\end{tabular}

Source: Air Quality in Europe, EEA 2019 report.

Figure 3 reports the historical evolution of the urban population's share exposed to excessive pollutant limits computed by the EEA since 2000. The percentage is calculated as the share of urban population exposed to airborne pollutant concentrations exceeding the limit value set by EU legislation. All the pollutants considered show a constant decreasing trend, making it possible to reach minimum levels between 2015 and 2017.

The percentage is calculated as the share of urban population exposed to airborne pollutant concentrations exceeding the limit value set by EU legislation. For $\mathrm{PM}_{2.5}$, the EEA considers the population exposed to annual concentrations above $25 \mu \mathrm{g} / \mathrm{m}^{3}$, for $\mathrm{PM}_{10}$ the population exposed to daily concentrations exceeding $50 \mu \mathrm{g} / \mathrm{m}^{3}$ for more than 35 days a year, for ozone the population exposed to maximum daily 8-hour mean $\mathrm{O} 3$ concentrations exceeding $120 \mu \mathrm{g} / \mathrm{m}^{3}$ for more than 25 days a year and for $\mathrm{NO}_{2}$ the population exposed to annual concentrations above $40 \mu \mathrm{g} / \mathrm{m}^{3}$. 


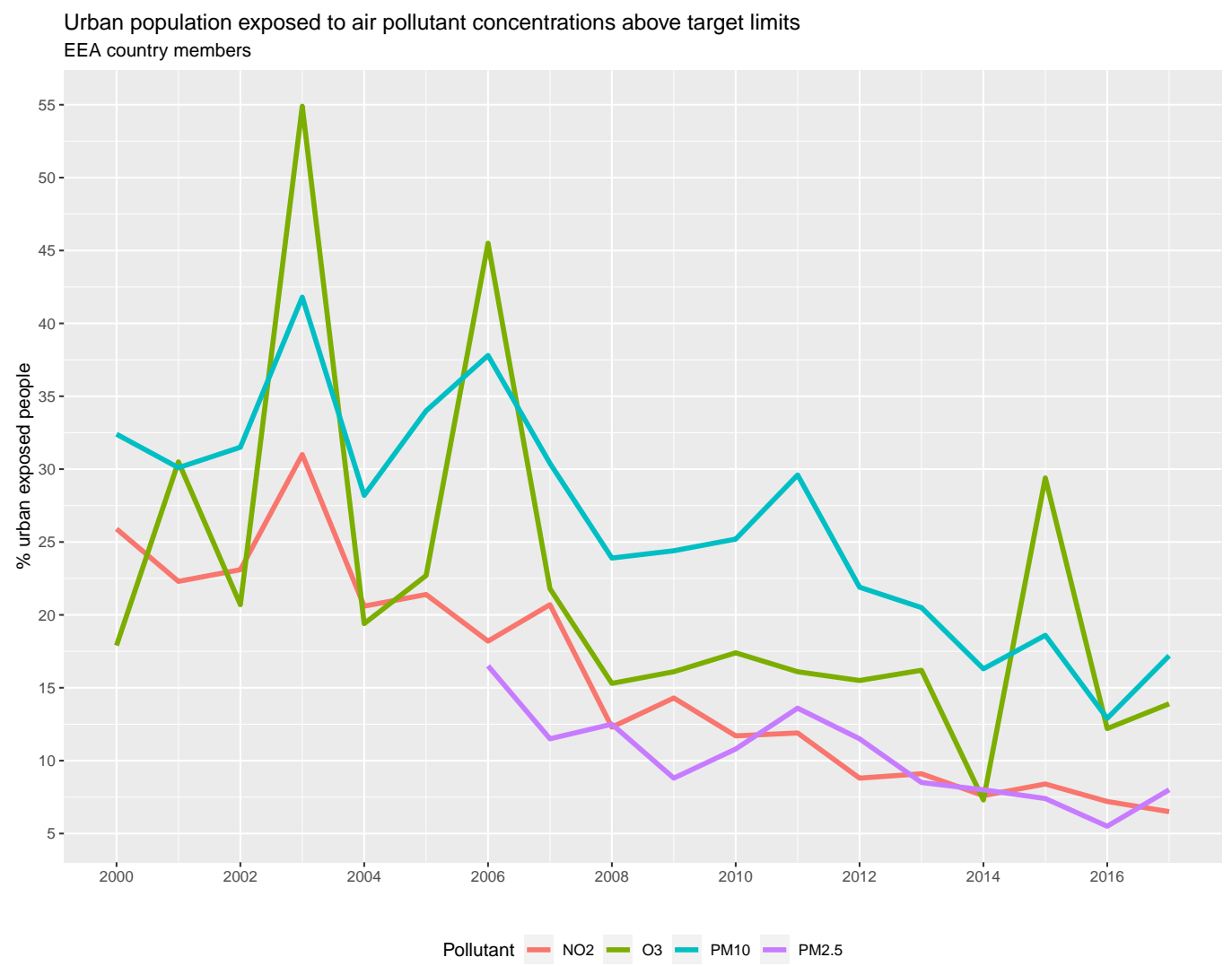

Figure 3. Urban population exposed to air pollutant concentrations above target limits from 2000 to 2017. Source: EEA webiste in 2020.

\subsection{Particular Matter (PM) Dynamic in Europe}

Concentrations of particulate matter (PM) continued to exceed the EU limit values in large parts of Europe in 2017. In particular, for PM with a diameter of $10 \mu \mathrm{m}$ or less $\left(\mathrm{PM}_{10}\right)$, concentrations above the EU daily limit value were registered at above $20 \%$ of the reporting stations in 23 over of the EIONet country members. For $\mathrm{PM}_{2.5}$, concentrations above the annual limit value were registered at $7 \%$ of the reporting stations in 10 reporting countries. The long-term EU AQG for $\mathrm{PM}_{10}$ was exceeded at $51 \%$ of the stations, whereas the long-term limit for $\mathrm{PM}_{2.5}$ was exceeded at $69 \%$ of the stations located in almost all the reporting countries.

As presented in Figure 2, emissions from the commercial, institutional and households sectors account for over half of the current primary $\mathrm{PM}_{2.5}$ emissions for the EEA region. Within this sector, emissions are almost exclusively from households, over $95 \%$, and current emissions are 7\% lower than those in 1990. Emissions from road transport account for approximately $11 \%$ of total $\mathrm{PM}_{2.5}$ emissions in EEA country members, but account for about $20 \%$ of the reduction in total emissions since 1990. This reflects the improved emission control technologies that have been introduced, particularly for diesel vehicles.

A total of $17 \%$ of the EU-28 urban population was exposed to $\mathrm{PM}_{10}$ levels above the daily limit value, and $44 \%$ was exposed to concentrations exceeding that.

Figure 4 gives a graphical representation of the above situation: the concentrations of particular matters remain in the atmosphere for long periods and maintain much higher levels, both in terms of time and quantity, than the limits set. The Italian Po Valley situation and many areas of Eastern European countries and Turkey seem to be particularly serious; in 2018, the concentrations in those areas exceeded the limits for over 50 days, with daily average values close to $50 \mu \mathrm{g} / \mathrm{m}^{3}$. 

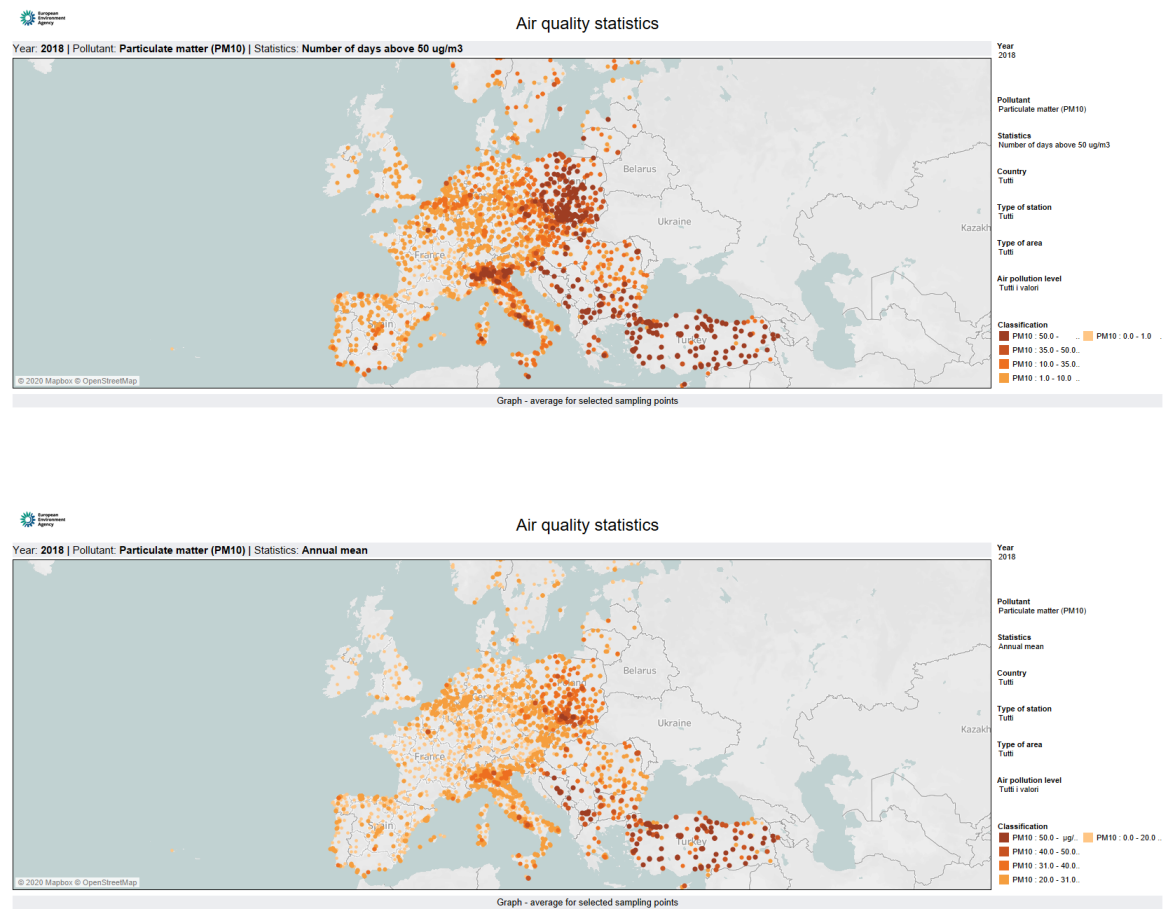

Figure 4. Number of days in which $\mathrm{PM}_{10}$ exceeded the the limit value of $50 \mu \mathrm{g} / \mathrm{m}^{3}$ (top panel), and average concentrations of $\mathrm{PM}_{10}\left(\mu \mathrm{g} / \mathrm{m}^{3}\right)$ in 2018 (bottom panel). Source: EEA website.

Figure 5 shows the distribution of $\mathrm{PM}_{2.5}$ concentrations by country in 2017. The plot highlight how EEA country member has very different and heterogeneous pollution levels. Some countries, in particular the Balkans and Eastern European countries, reach concentrations greater than 2 or 3 times those of the Scandinavian or Central European countries. Italy is characterized by a median level lower than the EEA limit (fixed at $25 \mu \mathrm{g} / \mathrm{m}^{3}$ for $\mathrm{PM}_{2.5}$ ), but with high variability that leads the country to exceed frequently the maximum limit value set by EU legislation.

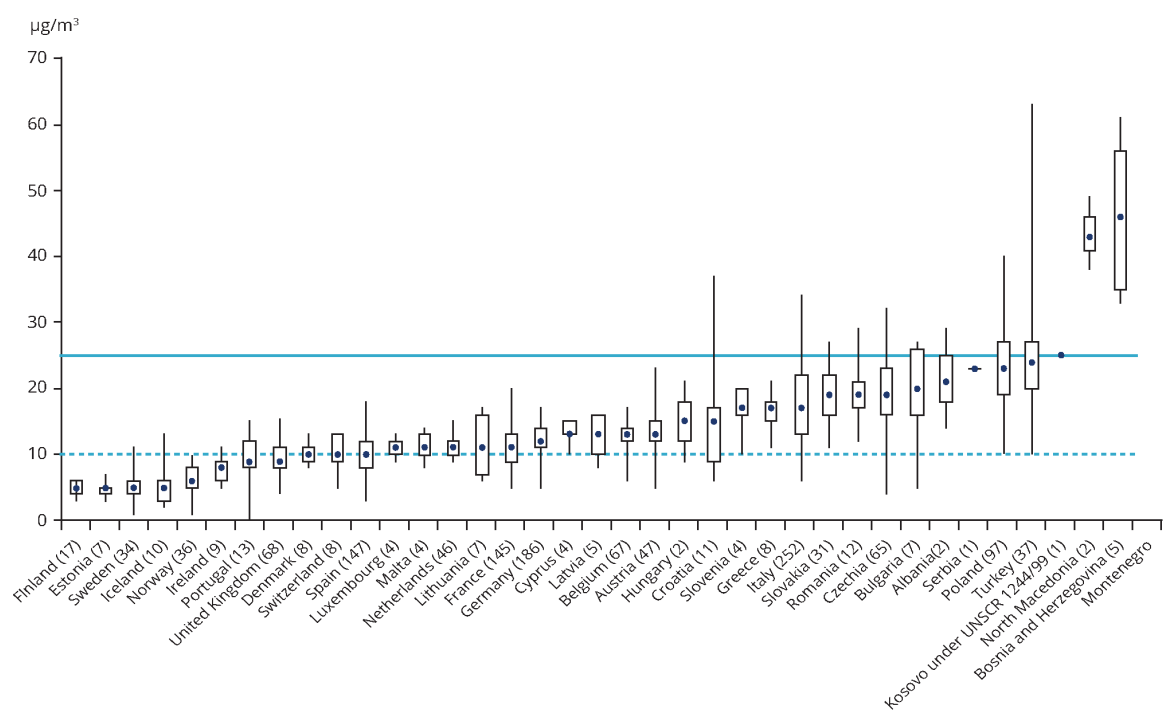

Figure 5. Average concentrations $\left(\mu \mathrm{g} / \mathrm{m}^{3}\right)$ of $\mathrm{PM}_{2.5}$ in 2017 for all the EEA country members. Rectangles are box-plots with an upper limit and lower limit corresponding to the maximum and minimum concentration observed, respectively. Values in parenthesis are the number of stations considered by country. The limit value set by EU legislation is marked by the horizontal line. Source: EEA website. 


\subsection{Nitrogen Oxides $\left(\mathrm{NO}_{X}\right)$ Dynamic in Europe}

Concentrations above the annual limit value for nitrogen dioxide $\left(\mathrm{NO}_{2}\right)$ are still widely registered across Europe, even if concentrations and exposures continue to decrease. In 2017 , around $10 \%$ of all the reporting stations recorded concentrations above EU standards. These stations were located in 20 reporting countries, 16 belonging to EU-28 and 4 nonEU members. In total, $86 \%$ of concentrations above this limit value were observed at traffic stations.

The $\mathrm{NO}_{2}$ dynamics just described tell a very similar story to particular matters and summarized by Figure 6. In fact, the oxides have very high values in vast areas of Europe, particularly Italy, in the industrial belt between Germany, France and Benelux and at specific points near major cities.

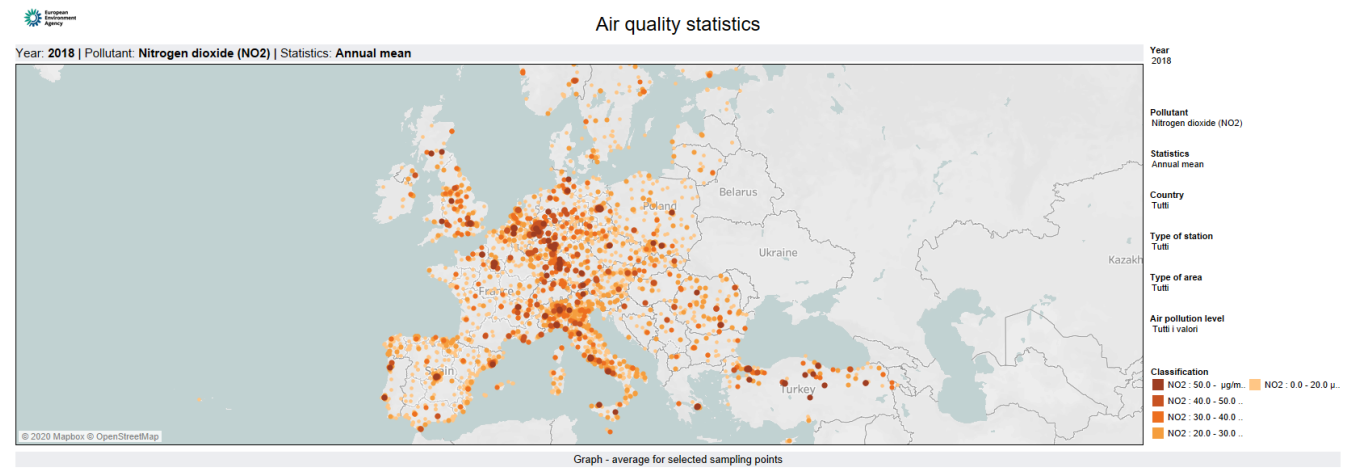

Figure 6. Average concentrations of $\mathrm{NO}_{2}\left(\mu \mathrm{g} / \mathrm{m}^{3}\right)$ in 2018. Source: EEA website.

Emissions from road transport and non-road transport combine to account for around half of the current $\mathrm{NO}_{X}$ emissions in the EEA members. Since 1990, there have been considerable reductions in $\mathrm{NO}_{X}$ in the road transport sector, despite the general increase in transport activity within this sector over the period. This sector alone has contributed to over $40 \%$ of the total reduction in nitrogen oxides emissions. Emissions of $\mathrm{NO}_{X}$ have also declined in the energy production and distribution sector, and current emissions are at approximately $40 \%$ of the emission level of 1990 . This dynamic is well illustrated in the two previous graphs.

Figure 7 shows the distribution of $\mathrm{NO}_{2}$ concentrations for all the EEA country members. As other important countries, such as France and Spain, Italy reports values in line with the largest part of European countries, but sometimes presents very high and abnormal values in terms of nitrogen dioxide concentrations.

The upper tail of the distribution (over the 75th percentile), in fact, is characterized by extreme values well above the median and the rest of the distribution.

In addition to the main pollutants discussed above, in 2017, the European Environmental Agency launched a new overall air quality index for EEA member and reporting countries in order to provide to the society an easy and intuitive tool to evaluate and compare the air we breathe. The new European Air Quality Index (EAQI) (https:/ / www.eea.europa.eu/themes/air/air-quality-index, accessed on 20 January 2021) reflects the potential impact of air quality on health, driven by the pollutant for which concentrations are poorest due to associated health impacts. The index substitutes the previously existing Common Air Quality Index [36] and provides information on the local air quality of about 2000 locations across Europe and is constructed by aggregating the observed concentrations of particulate matter $\left(\mathrm{PM}_{2.5}\right.$ and $\left.\mathrm{PM}_{10}\right)$, ground-level ozone $\left(\mathrm{O}_{3}\right)$, nitrogen dioxide $\left(\mathrm{NO}_{2}\right)$ and sulphur dioxide $\left(\mathrm{SO}_{2}\right)$. The EAQI returns the short-term (hours or days) air quality near each station using a 6-levels Likert scale associating at each level of the scale a different message to the European population and providing particular attention to the population most at risk. In general, when EAQI increases, public health risks increase. 


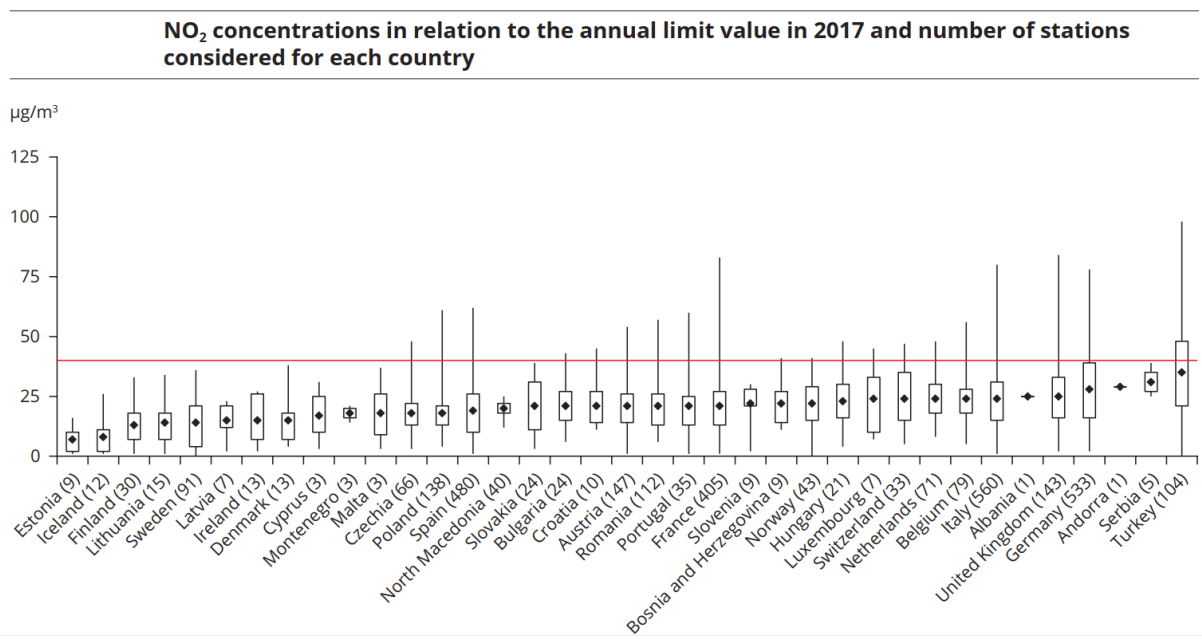

Figure 7. Average concentrations $\left(\mu \mathrm{g} / \mathrm{m}^{3}\right)$ of $\mathrm{NO}_{2}$ in 2017 for all the EEA country members. Rectangles are box-plots with an upper limit and lower limit corresponding to the maximum and minimum concentration observed, respectively. Values in parenthesis are the number of stations considered by country. The horizontal line marks the limit value set by EU legislation. Source: EEA Air quality in Europe 2019.

\section{The Italian Environmental Protection System and ARPA Lombardia Monitoring System}

Italy being an EU member state, Italian institutions are primarily involved in the European system of environmental protection. The Italian regions, through the ARPA agencies, are entrusted with the important task of monitoring local air pollution and meteorology, creating scientific reports on a periodic basis and disseminating as much information as possible to citizens and institutions. Each ARPA monitors the atmosphere through a dense ground monitoring network composed mainly by permanent stations, but also by mobile samplers.

The Italian environmental protection system, translated as Sistema Nazionale per la Protezione Ambientale (SNPA) (https: / / www.snpambiente.it/chi-siamo/, accessed on 20 January 2021), is a national institution whose competences and objectives range from the protection and monitoring of environmental quality to local supervision and controls up to the scientific research. It is composed of the Istituto Superiore per la Protezione e la Ricerca Ambientale (ISPRA) and a local environmental protection agency for each region Agenzie Regionali Protezione Ambiente or ARPA. In the Italian case, the system counts 19 ordinary agencies, an agency for the Bolzano autonomous province and another for Trento autonomous province.

SNPA activities are strictly connected to the political and administrative system and provide to decision-makers useful tools for policy actions, both in the short-run and in the long-run, and technical-scientific support. The system was established in 2016 through the law n. 132/2016 [37], complementing the constitutive process of the individual ARPAs, begun in the $90 \mathrm{~s}$, and inserting Italy in the European Union context environmental protection.

The main activities carried on by the SNPA are the following:

- Inspection activities and environmental control;

- Monitoring of the state of the national environment;

- Control of water sources and pollution emissions;

- Technical-scientific support to the activities of state, regional and local bodies that have active administration tasks in the environmental field;

- Collection, organization and dissemination of environmental data, reports, research and statistical analysis which constitute an official technical reference to be used for the purposes of the public administration activities. 
Moreover, it expresses its binding opinion on the Government and local authorities' provisions regarding the environment. It indicates the opportunity for interventions, including legislative ones, to pursue sustainable development objectives, the reduction of land consumption, safeguarding and promoting the quality of the environment and the protection of natural resources.

The last listed activity consists in collecting and providing data on the Italian environmental situation, both at local and national levels, through the environmental informative system (Sistema Informativo Nazionale Ambientale or SINA), locally managed by each territorial ARPA.

The Italian SNPA is part of the European Environment Information and Observation Network (EIONet) (https: / / www.eionet.europa.eu/, accessed on 20 January 2021), a European partnership network managed by the European Environmental Agency (EEA) (http: / / www.eea.europa.eu/, accessed on 20 January 2021) aiming at uniforming, coordinating and spreading the national informative systems. EIONet consists of the EEA itself, eight European Topic Centres (ETCS) and a network of around 400 national environment agencies and other bodies dealing with environmental information [38]. EIONet gathers information by all the EU member countries plus Iceland, Norway and Balkans countries. The data collection process that EIONet partner institutions must respect consists of three consecutive steps. In the first stage, local agencies (such as ARPA Lombardia for their region) collect raw data through their own monitoring system; data are then processed and aggregated at regional level (step 2) and then processed and aggregated at national level (step 3). In the EIONet context, each national informative system is referred as National Focal Point $(N F P)$, and it cooperates mutually with all the other members and the central agency. The mutual collaboration is also carried out through national research centers and international consortia dealing with specific environmental topics and contracted by the EEA to perform specific tasks of its work program. ISPRA plays the role of National Reference Centre (NRC) for Italy.

According to the EEA-EIONet system, national data on air pollution concentration are collected at the local level and directly managed by the regional agencies for environmental protection. Recall from Section 4 that the Italian monitoring network is composed by twenty-one regional agencies, named ARPAs, and by a central institution called ISPRA, which coordinates the regional bodies.

\subsection{The Role of ARPA Lombardia}

Being the institution responsible for local environmental protection and air quality, the ARPA monitoring system controls the main meteorological and hydrogeological measurements. Each regional agency owns a territorial monitoring network consisting of fixed and mobile ground stations. Stations can gather information on air quality, on meteorology or both. Installation, management, maintenance, replacement and calibration of the stations are under the agencies' responsibility, which must also provide IT and analytical tools, e.g., databases and dashboards, necessary to spread knowledge about collected information to the public. In the following, we will also refer to stations with the term control units.

ARPA Lombardia is responsible for the collection and dissemination of data on air quality data, meteorology and emission inventories to other local authorities/administrations and to the citizenship. The primary air quality related tasks assigned to the agency are:

- Design, construction and management of the air quality monitoring network;

- Application of statistical and mathematical models of dispersion of pollutants in the atmosphere for near real-time and forecast evaluations;

- Scenario studies on the effects of policy actions;

- Development and updating of the inventory of INEMAR (AIR Emissions Inventory) emissions, which makes it possible to know the sources of the main air pollutants in each Lombard municipality, broken down by combustion and activity;

- Collection, processing and dissemination of data and report; 
- Participation in technical-scientific discussions on sector issues set up by the European Commission, the Ministry of the Environment, the Higher Institute for Environmental Protection and Research, the Lombardy Region and local authorities.

ARPA Lombardia also manages the hydro-meteorological service, which provides a public service of meteorological forecast and real-time hydro-meteorological monitoring: this knowledge base has numerous applications, for example, protection from natural risks, management of water resources and environmental protection. All data acquired by the monitoring networks are validated, archived and made available to the public, both in raw format and processed in analysis products (daily, weekly, monthly, yearly bulletin). Meteorologists process weather forecasts based on numerical weather modeling and observational data, and they are constantly updated to meet the user's specific needs.

Concerning the meteorology, among the others, ARPA Lombardia provides the following hydrogeological services:

- Weather monitoring and forecasting;

- Processing, archiving and dissemination of meteorological, hydrological and climatological data;

- $\quad$ Reporting of meteorological, hydrological and climatological analysis;

- $\quad$ Research and development in the context of national and international projects.

The whole database concerning atmospheric concentrations, emission inventories and meteorology collected by ARPA is freely accessible to public users. The data can be consulted and downloaded through two official channels: the first is the specific web dashboard promoted by ARPA Lombardia (https:/ / www.arpalombardia.it/Pages/Aria/ qualita-aria.aspx, accessed on 20 January 2021), which also provides real-time mapping of air and water quality in addition to periodic reporting; the second channel is the open database owned by Lombardy regional administration (https:/ / www.dati.lombardia.it/, accessed on 20 January 2021), an open-source portal which contains all the territorial statistics regarding the environment, energy, local government, health, culture, productive activities and others. Moreover, starting in 2021, it is possible to freely download data through an $\mathbf{R}$ [39] package called ARPALData available from the CRAN repository.

The open-access database contains information about air quality and weather measures collected through the ground sensors and descriptive information on the stations: unique identifiers of each station belonging to the monitoring network, geographical coordinates, administrative membership (province or other administrative aggregations) and municipality, the service start date and the eventual disposal date. This last case implies that the sensor, or the entire station, has been deactivated and no longer produces information. Full description of air quality station registry is available at the link https:/ /www.dati. lombardia.it/Ambiente/Stazioni-qualit-dell-aria/ib47-atvt (accessed on 20 January 2021) and at https:/ / www.dati.lombardia.it/Ambiente/Stazioni-Meteorologiche/nf78-nj6b (accessed on 20 January 2021) for the weather stations.

\subsection{ARPA Lombardia Air Quality Ground Monitoring Network}

At the present date, air quality detection network in Lombardy consists of 84 ground stations using automatic analyzer tools and providing continuous measurements at regular time intervals, generally on an hourly or daily basis, depending on the pollutant of interest. On the monitoring stations are installed 495 sensors, each of them measuring a single type of pollutant among those available. The number of sensors for each station ranges from 1 to 14 , with a median value of 5 pollutants.

The monitoring stations consist of a basic structure, instruments for measuring atmospheric pollutants and equipment for displaying, processing and transmitting the measured parameters' values. All the air quality control units are equipped with a storage unit that allows to acquire the data measured by the instrumentation and provide for their transmission to the processing center. The atmospheric pollutant analyzers' main feature is to determine, automatically and continuously over $24 \mathrm{~h}$, the measurement of the substance under examination with high sensitivity, even when present in low concentrations. Technical details on the physical- 
chemical methodologies for detecting pollutants and on instrumentations can be retrieved from the ARPA Lombardia site, https://www.arpalombardia.it/Pages/Aria/Rete-dirilevamento/Criteria-di-rilevamento.aspx?firstlevel=Rete\%20di\%20rilevamento (accessed on 20 January 2021) section detection criteria.

The instrumentation installed in the air quality monitoring stations, operating $24 \mathrm{~h} \mathrm{a}$ day 365 days a year, is periodically subjected to checks and maintenance, aimed at ensuring the proper functioning of the equipment over time and the given product's reliability. ARPA Lombardy activated the so-called quality assurance procedures to guarantee the data's quality and accuracy. An independent team, comparable to an audit team of the financial and corporate world, carries out specific checks of quality control and quality assurance activities to ensure that the entire network functions adequately and that the data produced throughout the stations are high quality and comparable. For example, in the field audits, the audit office's analyzers, which represent the regional reference for a specific air pollutant, operate for a certain period in parallel with the network instrumentation. Any discrepancies found are investigated to identify the reason and intervene from a technical perspective to restore a correct measurement. The more two data are aligned, the more reliable the instrument is.

The stations are distributed throughout the regional territory on the basis of the Evaluation Program (PDV), which accounts for the population density and the type of environmental context. The number of fixed stations generally depends on the zoning of the territory and is a function of the population of each area and the state of air quality. The zoning of the territory is foreseen in zones and agglomerations on which to assess compliance with the target values and limit values. As represented in Figure 8, the territorial distribution covers all the provinces and pays particular attention to the central belt, i.e., Milan, Monza, Bergamo and Brescia provinces, which corresponds to the industrial and most dense area.

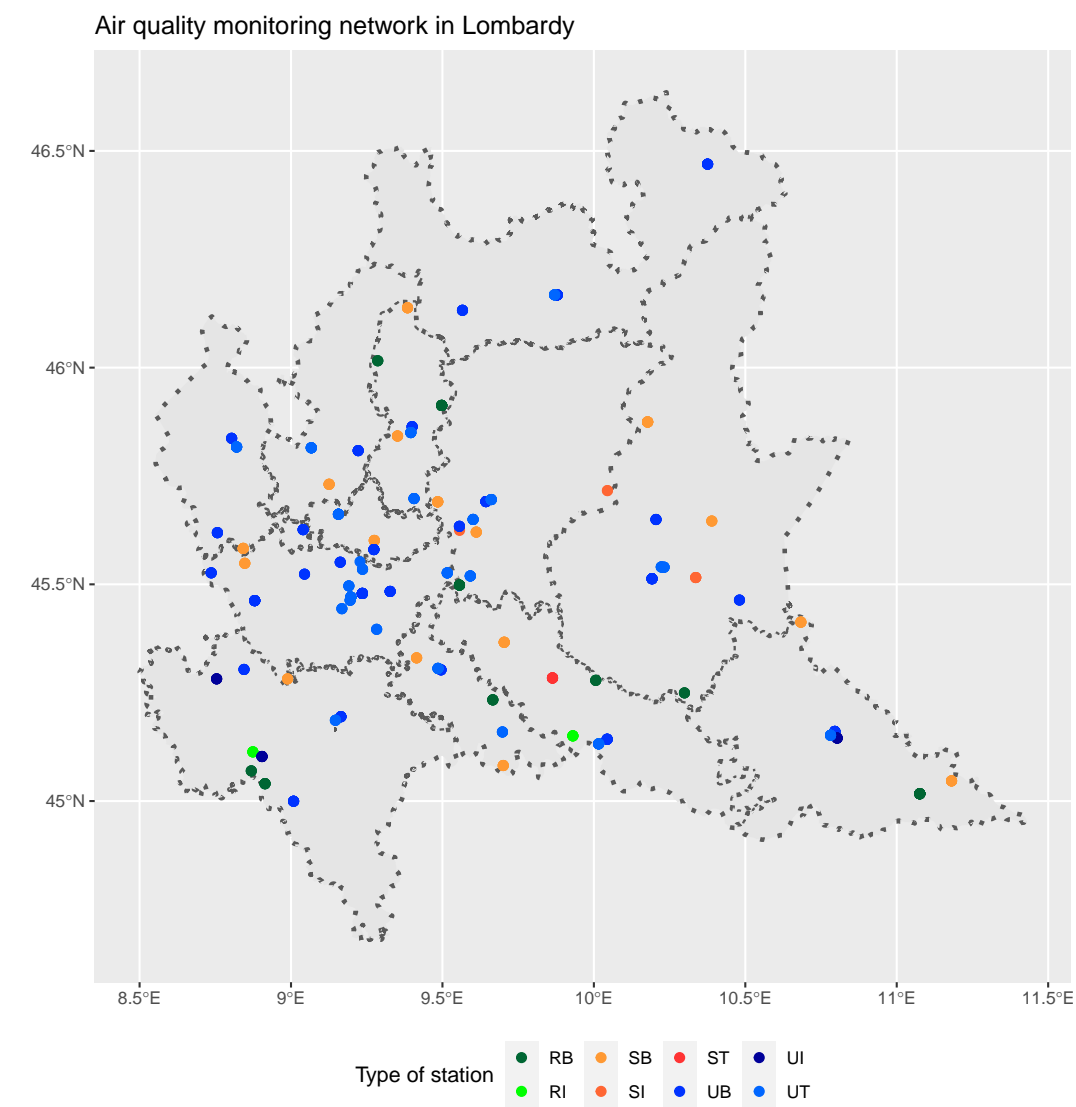

Figure 8. Regional distribution of air quality stations by typology. Source: ARPA Lombardy. 
Depending on the environmental context (urban, industrial, traffic or rural) in which the monitoring is active, the type of pollutants that must be detected is different. Therefore, not all stations are equipped with the same technical instrumentation. Since the network is constantly updated, thanks to improvements in technical equipment or the replacement of obsolete components, the control units can be installed in different years or interrupt their life cycle prematurely. This is an important factor generating heterogeneity of the monitoring network and consequently of the data available. In other words, stations can measure different types of pollutants with different periods of functioning.

EEA and ARPA classify air quality control units according to the environmental context in which they are active. We can distinguish two classes of classifications: the first depending on the distribution (density) of buildings and the type of area surrounding the installation site and a second based on the predominant emission sources recorded by the monitoring station [35]. The first classification clusters the stations in urban (U), suburban (S) and rural (R) stations. Urban stations are units installed in continuously built-up urban areas, suburban stations are installed in largely built-up urban areas, while rural stations provide information on sparsely populated areas. The second classification divides the stations in the background (B), i.e., pollution levels are representative of the average exposure of the general population or vegetation, traffic (T), i.e., stations located close to a single major road, and industrial (I), i.e., stations located near an industrial area or an industrial source. The combination of the two classifications allows identifying the functioning of any station properly. For example, a station labeled as UT describes a control unit installed in a large urban center near a highly-traffic zone; a station labeled as $R B$ describes a station capturing background pollutants in a rural area. Table 4 reports the classifications by area type and emission source for the stations currently active in the Lombardy region. The numbers show a predominance of urban stations (U) for the type of area and of the background (B) stations for the emission source. Rural (R) or industrial (I) monitoring units, on the other hand, are the minority.

Table 4. Classification of air quality stations by type of area and by predominant emission sources.

\begin{tabular}{|c|c|c|c|c|c|}
\hline \multicolumn{3}{|c|}{ By Type of Area } & \multicolumn{3}{|c|}{ By Emission Source } \\
\hline \multicolumn{2}{|c|}{ Classes } & \multirow{2}{*}{$\frac{\text { \# Stats }}{53}$} & \multicolumn{2}{|c|}{ Classes } & \multirow{2}{*}{$\frac{\text { \# Stats }}{25}$} \\
\hline Urban & $\mathrm{U}$ & & Traffic & $\mathrm{T}$ & \\
\hline Suburban & $S$ & 20 & Background & $\mathrm{B}$ & 49 \\
\hline Rural & $\mathrm{R}$ & 11 & Industrial & I & 8 \\
\hline
\end{tabular}

The airborne pollutants monitored by the ARPA stations are reported in Table 5. The table also contains information about the time coverage, collection frequency and the number of sensors installed for each airborne pollutants.

\subsection{ARPA Lombardia Meteorology Ground Monitoring Network}

Parallel to the environmental and air quality monitoring network, ARPA Lombardia also manages the automatic meteorological and hydro-geological monitoring network. The weather monitoring network counts on 984 sensors installed on 249 active stations. The regional agency makes available to the public meteorological data with a 10-minutes frequency starting from 1989 until the current month. As for the air quality stations, the weather control units are located homogeneously on the regional territory to return the most extensive spatial coverage possible. Figure 9 shows the spatial distribution of weather stations within the provinces. 
Table 5. Synthesis of the airborne pollutants monitored by ARPA Lombardia.

\begin{tabular}{cccc}
\hline Pollutant & Symbol & Frequency & Sensors \\
\hline Total nitrogen oxides & $\mathrm{NO}_{X}$ & Hourly & 88 \\
Nitrogen dioxide & $\mathrm{NO}_{2}$ & Hourly & 88 \\
Particulate matters 2.5 & $\mathrm{PM}_{2.5}$ & Daily & 10 \\
Particulate matters 10 & $\mathrm{PM}_{10}$ & Daily & 64 \\
Black carbon & $\mathrm{BC}$ & Hourly & 2 \\
Ozone & $\mathrm{O}_{3}$ & Hourly & 53 \\
Carbon Monoxide & $\mathrm{CO}$ & Hourly & 46 \\
Sulphur dioxide & $\mathrm{SO}_{2}$ & Hourly & 35 \\
Benzene & $\mathrm{C}_{6} \mathrm{H}_{6}$ & Hourly & 24 \\
Benzo(a)-pyrene & $\mathrm{C}_{20} \mathrm{H}_{12}$ & Daily & 14 \\
Ammonia & $\mathrm{NH}_{3}$ & Daily & 10 \\
Cadmium & $\mathrm{Cd}$ & Daily & 14 \\
Nickel & $\mathrm{Ni}$ & Daily & 14 \\
Arsenic & $\mathrm{As}$ & Daily & 14 \\
Lead & $\mathrm{Pb}$ & Daily & 14 \\
\hline
\end{tabular}

The sensors have been installed since the late 1980s and share the maintenance and installation process and the data quality standards, described above for the air quality stations. Table 6 summarizes the weather parameters measured by the meteorological monitoring network of ARPA Lombardia and provides the number of sensors for each variable and their unit of measurement. Overall, the network covers the whole regional territory (Figure 9), but the coverage can vary depending on the parameter considered. For example, temperature and precipitation are measured in more than 200 different sites in a homogeneous way (see Figures 19 and 21), while the sensors that monitor the snow height are located mainly in the northern Alps.

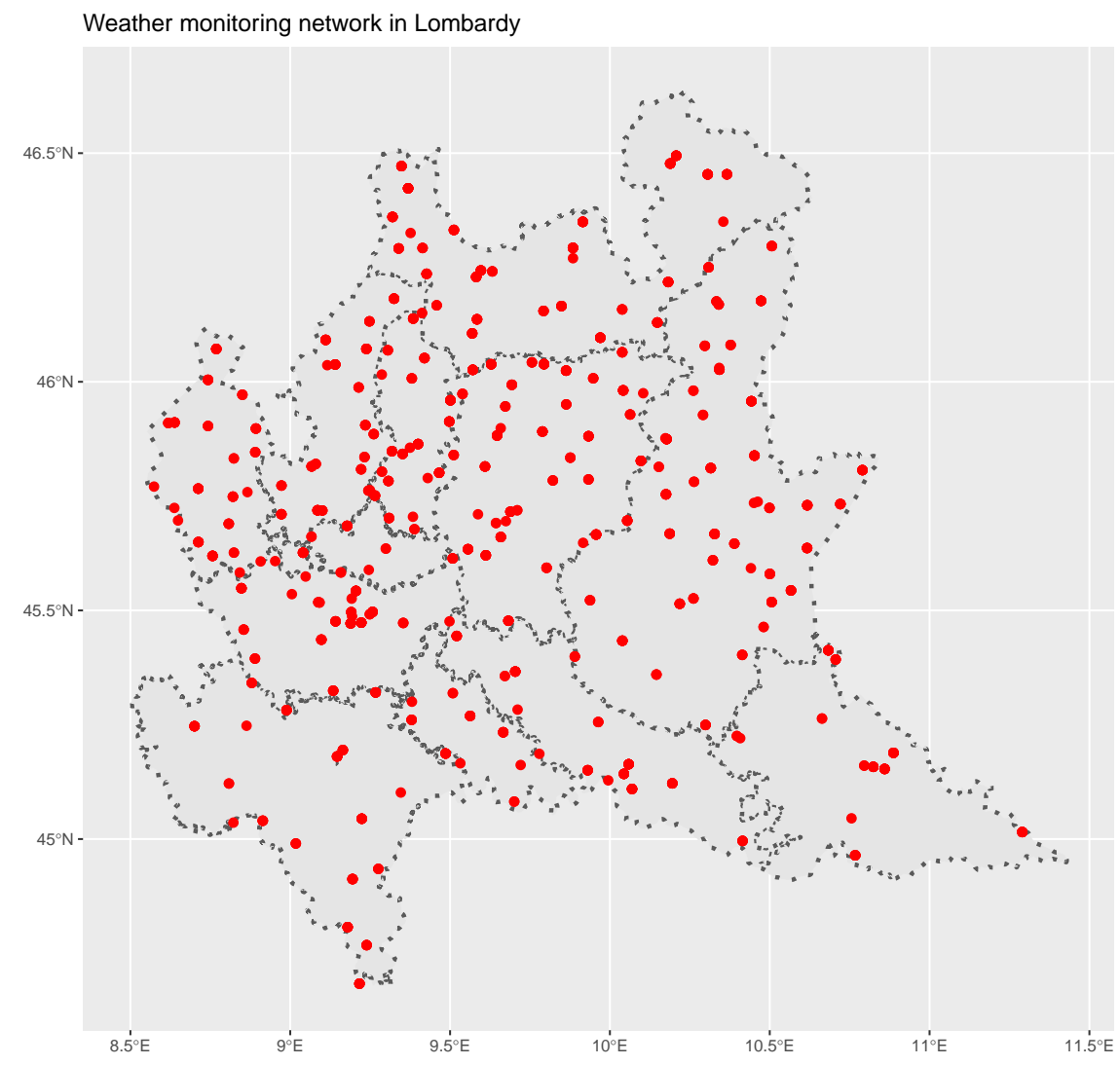

Figure 9. Regional distribution of meteorological stations in Lombardy. Source: ARPA Lombardia. 
Table 6. Synthesis of the weather parameters monitored by ARPA Lombardia and number of sensor currently installed for each parameter.

\begin{tabular}{ccc}
\hline Variable & Unit Measure & Sensors \\
\hline Temperature & Celsius degrees $\left(^{\circ}\right)$ & 205 \\
Rainfall & millimeters $(\mathrm{mm})$ & 223 \\
Solar global & watt per square metre & 94 \\
irradiance & $\left(\mathrm{W} / \mathrm{m}^{2}\right)$ & 160 \\
Relative humidity & percentage $(\%)$ & 126 \\
Wind speed & meter per second $(\mathrm{m} / \mathrm{s})$ & 126 \\
Wind direction & clockwise degrees $\left({ }^{\circ}\right)$ & 33 \\
Snow height & centimeters $(\mathrm{cm})$ & 65 \\
Water height & centimeters $(\mathrm{cm})$ & \\
\hline
\end{tabular}

Observed values of temperature, solar irradiance, relative humidity and wind speed and direction represent the average value recorded during the $10 \mathrm{~min}$ of reference, while rainfall and snow and water height are cumulated over time. Wind direction represents the direction of origin of blowing wind, and it is conventionally stored using north-degrees, i.e., ranging from $0^{\circ}$ to $360^{\circ}$, where $0^{\circ}$ and $360^{\circ}$ represent a wind blowing from the north and $90^{\circ}$ means that wind blows from the east.

\subsection{Emission Inventory for Lombardy}

As already mentioned, ARPA is also responsible for managing and deploying the regional emission inventory (namely INEMAR), which is an essential tool for air quality planning for local administrations and a useful data source largely used by public and private environmental organizations. The inventory is updated every 2 to 4 years. The first edition refers to 2003, while the latest available version refers to 2017 (currently under revision process). Available data refer both to the common airborne macro-pollutants $\left(\mathrm{SO}_{2}\right.$, $\left.\mathrm{NO}_{X}, \mathrm{CO}, \mathrm{NH}_{3}\right)$, micro-pollutants (particulates) and the main greenhouse gases $\left(\mathrm{CO}_{2}, \mathrm{CH}_{4}\right.$, $\mathrm{N}_{2} \mathrm{O}$ ). Emission inventory for Lombardy can be freely consulted through the INEMAR website (https:/ / www.inemar.eu/xwiki/bin/view/Inemar/WebHome, accessed on 20 January 2022), which allows an open-source distribution of raw data for researchers and all the subjects interested in the air quality topics.

ARPA makes available emission inventories up to the municipal level and classifies the emission sources according to the SNAP nomenclature of activities (Selected Nomenclature for sources of Air Pollution). INEMAR is organized respecting the European guidelines drawn up in EMEP-Corinair inventory guidebook, in particular, ARPA Lombardia adopted the Corinair SNAP-97 nomenclature integrated over the years the most significant and updated activities added to the basic nomenclature. A detailed report on the structure of the atmospheric emission inventory for the Lombardy Region and on the algorithms used to compute estimations has been realized by [40]. According to the EMEP-Corinair Emission Inventory approach, the SNAP-97 system [38] is set up according to three levels:

- The upper level (11 source categories) which features sources' grouping as commonly performed;

- The intermediate level (75 source sub-categories) comprehending technological and social-economic criteria;

- The lower level (485 source activities) aiming at an exhaustive enumeration of sources and sinks to spot homogeneous sections in generating emissions.

The upper level of INEMAR classification is composed of 11 macro-sectors:

- Combustion in energy and transformation industries;

- Non-industrial combustion plants;

- Combustion in the manufacturing industry;

- Production processes;

- Extraction and distribution of fossil fuels; 
- Solvent and other product use;

- Road transport;

- Other mobile sources and machinery;

- Waste treatment and disposal;

- Agriculture;

- $\quad$ Other sources and sinks.

The inventory also provides information about the emissions classified by fuel and estimates the average traffic emission factors to estimate road transport emissions. The emission factors are available for different levels of aggregation:

- By type of vehicle (cars, light vehicles, heavy vehicles and buses, mopeds and motorcycles);

- $\quad$ By type of road (motorways, suburban roads, urban roads);

- $\quad$ By fuel (petrol, diesel, LPG, methane);

- $\quad$ by legislative type, i.e., Euro category (from Euro 0 to Euro VI).

\section{Air Quality in Lombardy: Empirical Evidences}

\subsection{Why the Lombardy Case Study is Relevant?}

For many years, Northern Italy has been at the top of the ranking of the most polluted areas in Europe $[34,35]$. The Lombardy region is the geographic and economic epicenter of this area: it is organized in 11 provinces, and it counts on more than 10 million inhabitants and the highest gross domestic product per inhabitant of Italy, approximately 35 thousand Euros per capita $[41,42]$. The air quality recorded in the Lombardy region is a case of international relevance as, despite the efforts of the authorities to counteract the phenomenon of pollution, we still struggle to comply with international rules on concentrations.

The region can be geographically and economically divided into three zones: the mountain range of the Alps at North and the Apennine at South, the sloping foothills at the Middle-North, and the highly industrialized and populated basin of the Po River in the middle. Most of its major cities are located in the Po River basin, which crosses the entire region and acts as the southern natural border for many kilometers. As shown in the left panel of Figure 10, the Lombard basin is bordered on two sides by mountains, i.e., the southern and northern borders, which makes the atmospheric dispersion poor and which render air mass exchange very low. Wind speed measured in the Po River plain is among the lowest in Europe, about $1.5 \mathrm{~m} / \mathrm{s}$ on average, causing smog and pollution trapping close to the ground. According to a recent simulation study by [43], if Po Valley had the same meteorological conditions typical of central-northern Europe and kept the same emission levels, average monthly concentrations of $\mathrm{PM}_{10}$ and $\mathrm{NO}_{2}$ would be lowered by 60 to $70 \%$ and $60 \%$ compared to concentration levels of 2013 . Peaks of $70-80 \%$ reduction would be reached in the western Po Valley. Consequently, it is clear that it is more difficult for Po Valley regions to comply with international air quality standards compared to other EU and non-EU member states.

Besides, Lombardy counts many industrial facilities and small and medium enterprises for which road transport is an essential component for economic viability. According to INEMAR Emission Inventory of Lombardy 2017 [44], summarized here in Figures 11 and 12, industrial and non-industrial combustion plants and road transport represent more than $73 \%$ of particulate matter emission sources and more than $76 \%$ of nitrogen oxides emissions in the region. Regarding oxides, carbon dioxide and particulate matters, road transport emissions diverge significantly from the European levels, with values much higher than the EU average. In particular, in the metropolitan area of Milan, which will be the subject of a specific focus in the next chapters, road traffic alone is responsible for the emission of $65 \%$ and $69 \%$ of the total emissions of $\mathrm{NO}_{X}$ and $\mathrm{CO}$, respectively. Coherently with their anthropogenic emissions sources, fine particulate matters are mainly generated by wood-fired heating systems (i.e., wood), while oxides are generated by chemically treated fossil fuels and petroleum derivatives (i.e., diesel and oil). 


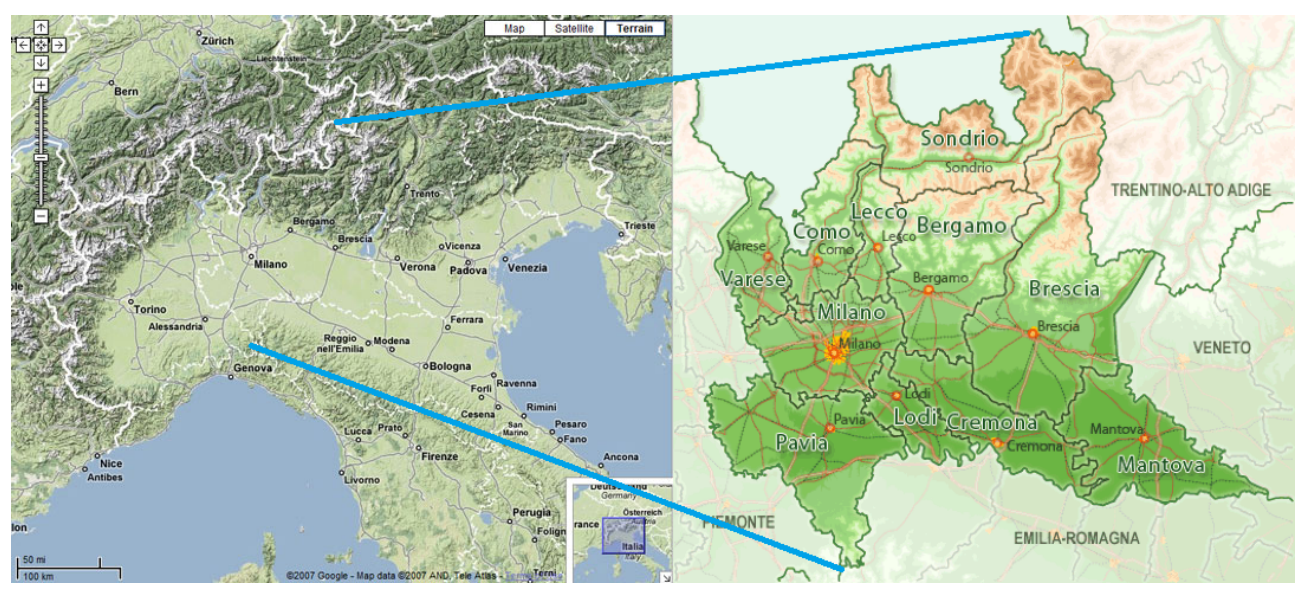

Figure 10. Location of Lombardy in Europe.

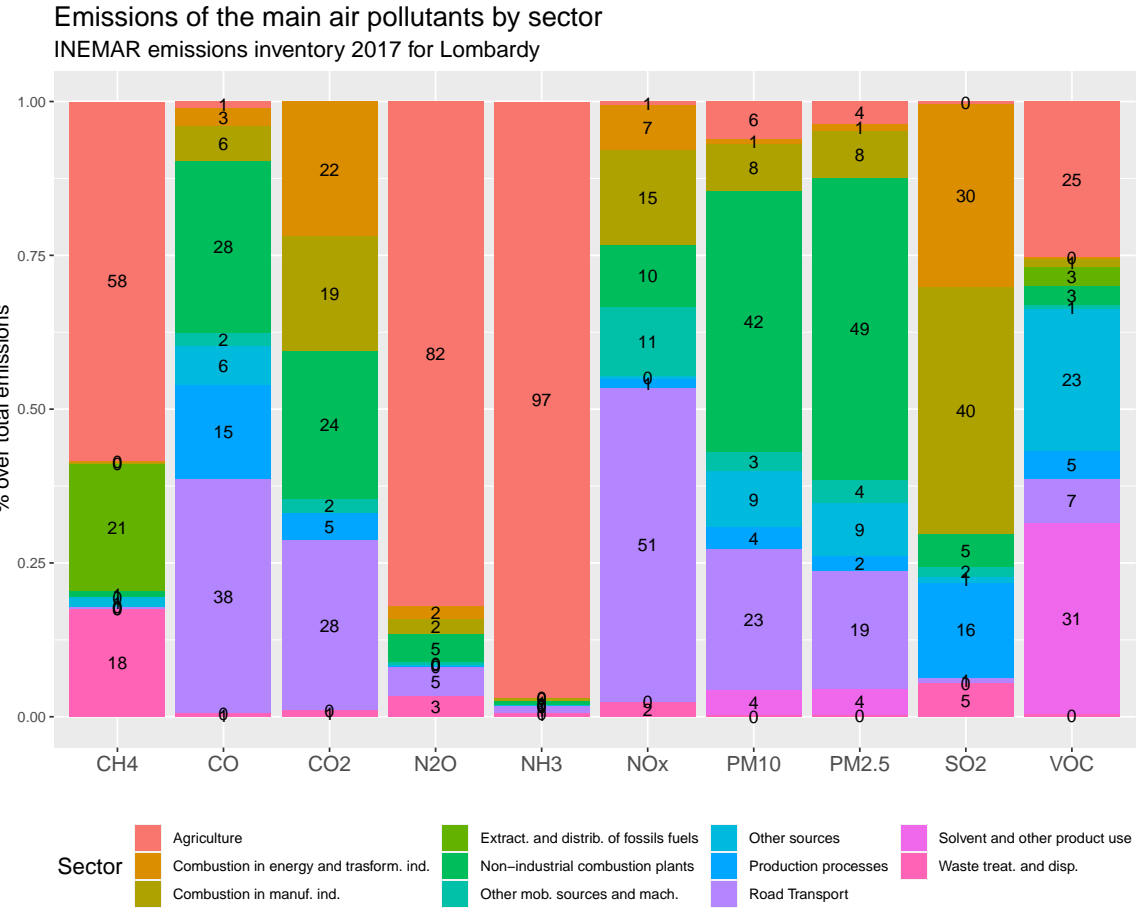

Figure 11. INEMAR Lombardia 2017 emissions by macrosectors. Source: INEMAR emission inventory for Lombardy.

Figure 12 also reports that the large part of other airborne pollutant emissions, particularly for ammonia, volatile organic compounds and methane, are due to non-combustible materials. The two figures also highlight that emissions from agricultural activities in Lombardy are the major source of pollution regarding methane $(\mathrm{CH} 4)$, nitrous oxide $\left(\mathrm{N}_{2} \mathrm{O}\right)$ and ammonia $\left(\mathrm{NH}_{3}\right)$, for which they amount, respectively, to $58 \%, 87 \%$ and $97 \%$. Regional agriculture land makes up around $69 \%$ of the total area. Lombardy is the first Italian region for agriculture production and contains 1.5 million bovines and 4 million swine, respectively, about $48 \%$ and $25 \%$ of the national headcount. The INEMAR 2017 inventory estimates that about $95 \%$ of total ammonia $\left(\mathrm{NH}_{3}\right)$ emissions in Lombardy are caused by livestock and fertilizers. Indirectly, atmospheric ammonia reacts with atmospheric nitric and sulfuric acids and turns to particulate matters, generating a consequent increase in $\mathrm{PM}_{2.5}$ concentrations [45]. 


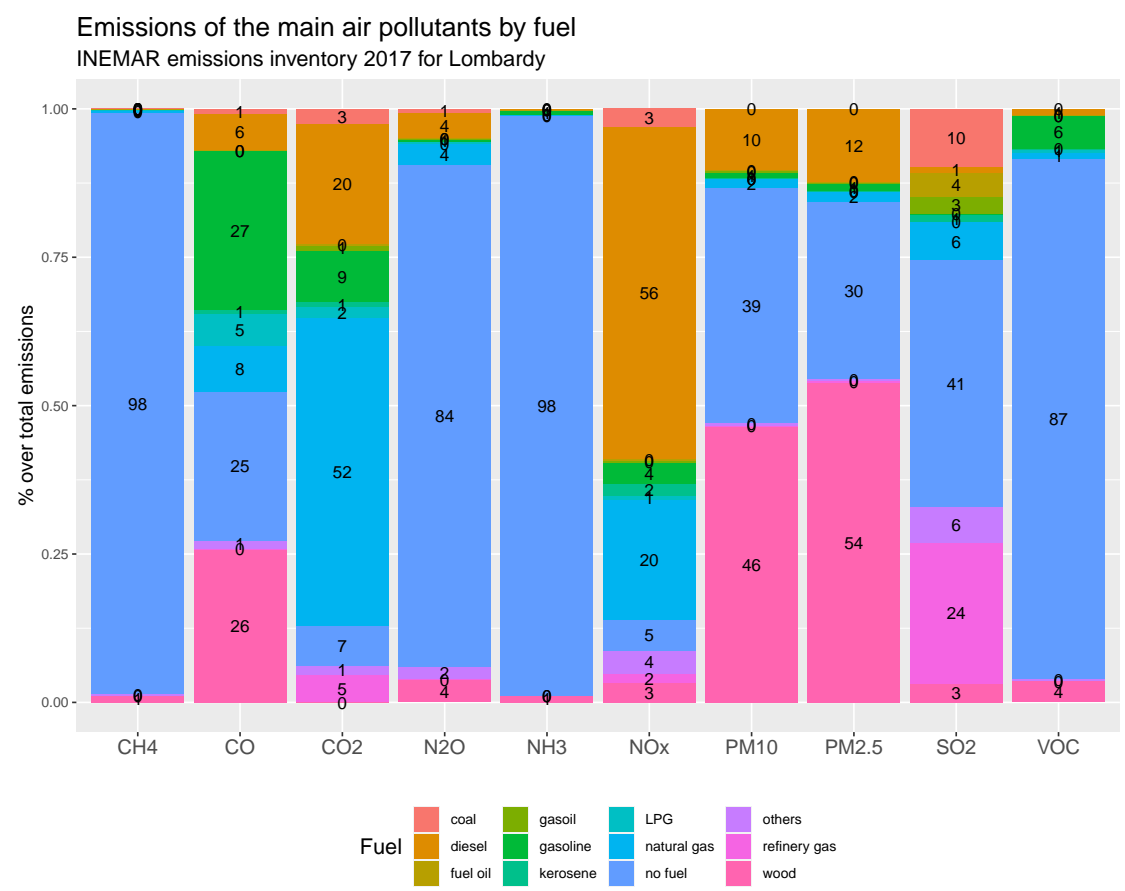

Figure 12. INEMAR Lombardia 2017 emissions by fuel type. Source: INEMAR emission inventory for Lombardy.

The Lombardy region is also the most densely populated country, with large and very dense urban agglomerations. The average population density in Lombardy is around 419.9 inhabitants $/ \mathrm{km}^{2}$, while only 200 inhabitants $/ \mathrm{km}^{2}$ at national level [41]. This fact also reflects on the spatial distribution of airborne emissions. As reported in Figure 13, the four largest and populated provinces, i.e., Milan (MI), Monza (MB), Bergamo (BG) and Brescia (BS), generated the $52 \%$ of total emissions of $\mathrm{NO}_{x}$ and the $51 \%$ of particulate matters in 2017.

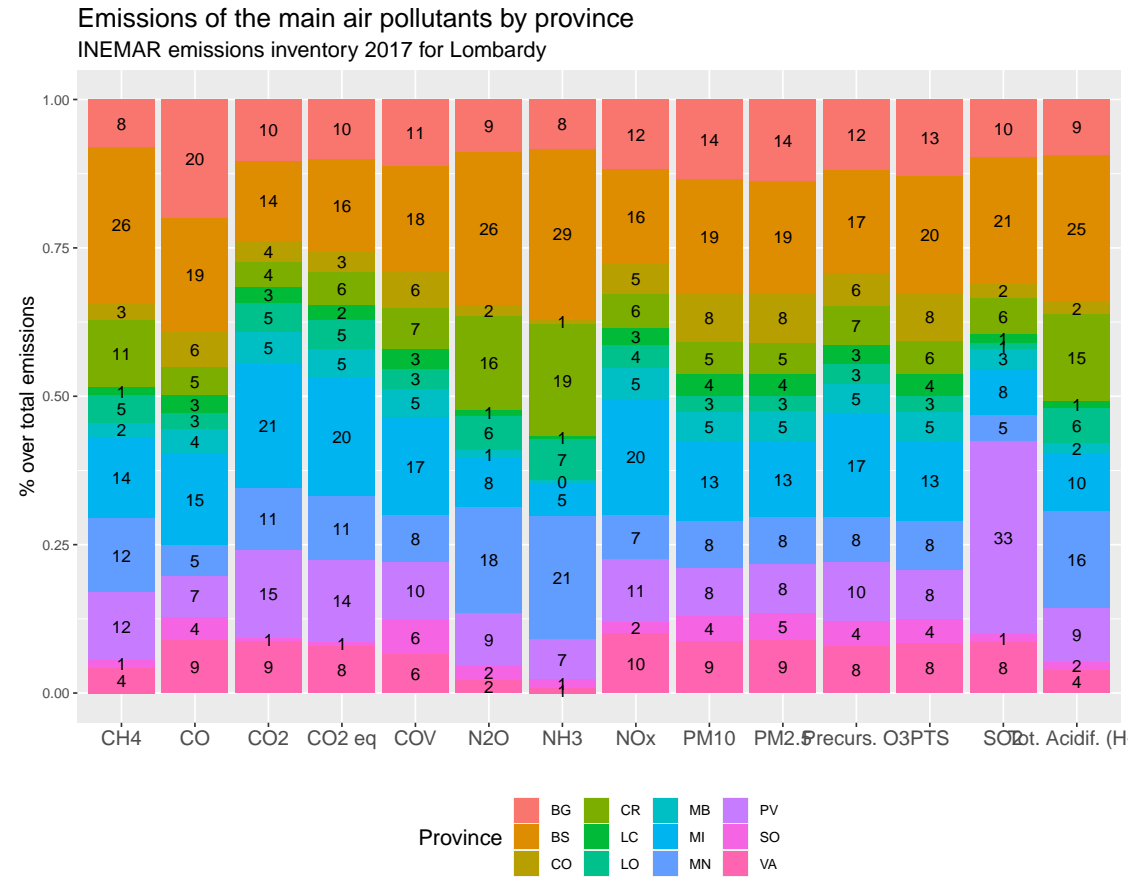

Figure 13. INEMAR Lombardia 2017 emissions by province. Source: INEMAR emission inventory for Lombardy. 
Overall, its unfavorable geographical context, aggressive land use, climate characteristics and emission sources create a high level of air pollution, therefore determining long favorable periods for accumulating pollutants.

The literature concerning the evaluation of the impacts of exposure to atmospheric pollutants has given considerable space to the case of Lombardy and, more in general, to Northern Italy. Many epidemiological studies conducted using Lombardy ARPA data provided strong evidence of the association between poor air quality exposure and shortand-log term effects on health, particularly the association with mortality. Recent studies performed meta-analyses to assess how much particulate matter and oxides affect people's health in many Lombardy locations, including Milan's urban areas, starting from the early 2000s. In [46], effects have been evaluated in terms of numbers of attributable deaths under some counterfactual scenarios of air pollution reduction based on WHO guidelines and European Union limits. The authors of [46] found that current annual $\mathrm{PM}_{10}$ levels are responsible for over than 13\% attributable death rates per year using EU limits. By reducing existing concentrations by a fifth, it could be possible to reduce by more than $30 \%$ the burden of short-term deaths linked to ambient air pollution. Other further factors to be considered studying the Lombardy case are the transport and commuting among municipalities. In fact, mobility in Lombardy is predominant, with the highest percentage in Italy of residents commuting daily to workplaces or schools, about 5 million incoming and out-going in 2013, half of them out of their residence municipality. The authors of [47] considered commuting data to estimate the very-short increase in mortality, i.e., within 2 days from the exposure, due to $\mathrm{PM}_{10}$ in Lombardy. Their findings suggest that the largest estimated impacts are placed along the Po River basin and in the largest cities. Commuting contributes to the spatial distribution of the estimated impact. In [48], the authors estimated the number of attributable deaths and hospital admission at the areal level through Poisson regression, showing that both $\mathrm{NO}_{2}$ and $\mathrm{PM}_{10}$ affect people differently based on the season and age of the patient and that to an increase of $10 \mu \mathrm{g} / \mathrm{m}^{3}$ in the average airborne levels is associated an increase in death rate up to $1.6 \%$. Moreover, [49] showed that although the average levels of particulate matter in Lombardy are progressively reducing, in all the most affected areas the population-weighted exposure levels decreased but never met the EU threshold.

Data from the open data of ARPA Lombardia are the main source used by researchers to highlight the local effects of public policies for environmental protection or to establish the ongoing atmospheric trends in the area. For example, see the studies of $[50,51]$ concerning the effects of traffic restricted zones in Milan on the concentrations of air pollutants, in particular nitrogen oxides. Considering the recent events caused by the COVID-19 pandemic, first of all the travel ban between municipalities and from cities, a crucial issue is the impact of restrictions on air quality in the Po Valley. In fact, this event constituted a natural experiment of historical magnitude that enabled researchers to quantify on a global scale the effects of potential reductions or minimization of human activities on the air pollution. The literature on the subject is very wide, but consider for example the reports of ARPA Lombardia [52] or scientific contributions such as [8,11,53-56].

\subsection{Evidence from ARPA Lombardia Data}

Using the ARPA Lombardia open database, we provide some empirical evidences about air quality and meteorology registered in Lombardy in the last few years. The objective we intend to achieve is to identify relevant short-run features of the regional atmospheric conditions using ARPA Lombardia data presented in the previous sections, as an example of how such data can be used. Specifically for weather measurements, we want to stress the fact that given the unfavorable morphology of the territory, which do not guarantee an adequate recycling of polluted air, meteorology seems to be a factor weakly able to clean the atmosphere and allow an improvement in air quality. The design and implementation of policies to reduce pollution and improve quality of life should take this into account. We recall that in this section we do not provide model-based statistical 
findings, but purely an empirical snapshot that captures some specific features and their short-term dynamics.

The data we will show focus on the short-run behavior of airborne pollutants and meteorology observed at aggregate level in Lombardy from January 2014 to November 2020. Regarding pollution, we analyze the measurements of oxides $\left(\mathrm{NO}_{2}\right.$ and $\left.\mathrm{NO}_{\mathrm{X}}\right)$, particulate matters ( $\mathrm{PM}_{10}$ and $\left.\mathrm{PM}_{2.5}\right)$ and ozone concentrations at weekly frequency, characterizing them with respect to the geography, the type of area (urban against rural area) and by emission sources. Meteorology will be analyzed at the aggregate regional level and typifying it with respect to the installed monitoring network. All the data presented have been collected through the $\mathbf{R}$ package ARPALData available from CRAN repository.

Figure 14 shows the weekly mean concentrations of the four pollutants recorded in Lombardy from January 2014 to November 2020. The regional mean is enhanced by $95 \%$ Gaussian confidence limits. Mean and standard errors have been obtained by aggregating weekly observations from all available stations active on the territory during the period. The seasonal behavior of the series is well defined: oxide and particulate concentrations reach maximum peaks during winter, while their minimum is reached in summer months; on the contrary, ozone is a summer pollutant that reaches severe levels in August and minimums during winters.

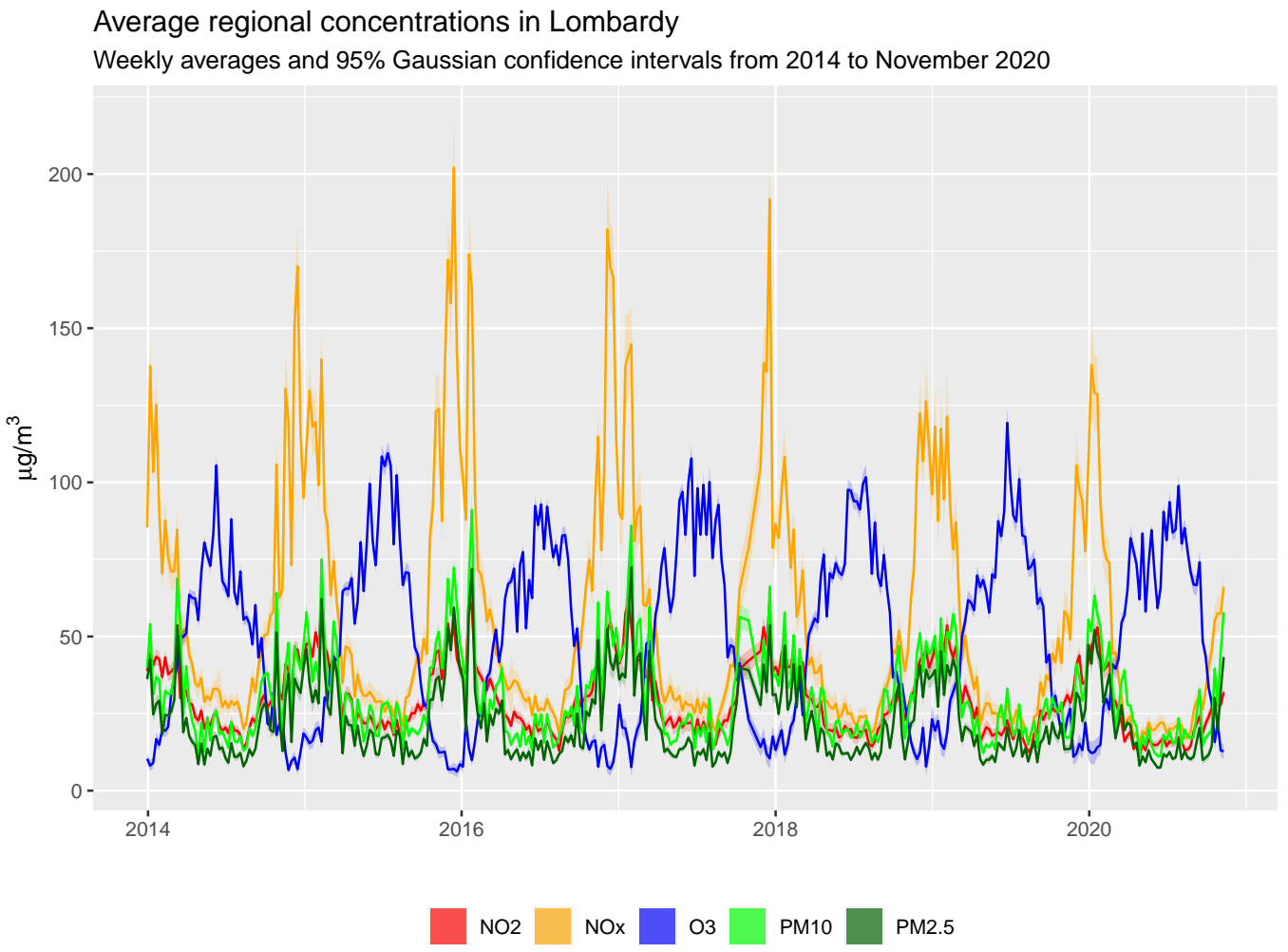

Figure 14. Average weekly concentrations of $\mathrm{NO}_{2}, \mathrm{NO}_{x}, \mathrm{PM}_{10}, \mathrm{PM}_{2.5}$, and ozone in Lombardy. Matt ribbons are the $95 \%$ Gaussian confidence bounds for the average.

Regarding oxide concentrations, both $\mathrm{NO}_{2}$ and $\mathrm{NO}_{x}$ show significant reductions in the maximum values observed, especially at the apex of winter, supporting the hypothesis of a generalized decreasing trend. Despite this, during the winter period, nitrogen dioxide concentrations show average values above the EU annual limit, which amounts to $40 \mu \mathrm{g} / \mathrm{m}^{3}$. The graph also reveals a similar pattern for particulate matters, defined by a period of very high concentrations between 2015 and 2018, and strong reductions in 2019 and 2020.

Figure 15 reports the weekly average concentrations for $\mathrm{NO}_{2}, \mathrm{NO}_{x}, \mathrm{PM}_{10}$ and $\mathrm{PM}_{2.5}$ according to the provinces in which they are recorded. Regarding oxide concentrations, the 
provinces of Monza-Brianza (MB), Milan (MI), Sondrio (SO) and Mantova (MN) are clearly identifiable and present very distant, and antithetical patterns. The first two provinces show predominant concentration levels compared to the others, being almost always above all the other provinces; whereas the last two always have the lowest values recorded. Considering a generic timestamp, the difference between the observed values of $\mathrm{NO}_{2}$ is stably in the range of $40-50 \mu \mathrm{g} / \mathrm{m}^{3}$. As said in Section 3, oxides are mainly generated by anthropogenic sources, in particular by combustion processes. The areas of Milan and Monza are rich in manufacturing and industrial activities, as well as being densely urbanized. Sondrio is an alpine province with only mountains, while Mantova is a large and flat area with several rivers and agricultural land. Both areas are sparsely populated. In terms of $\mathrm{PM}_{10}$ and $\mathrm{PM}_{2.5}$, the plot is more complex but still provides some important hints. None of the provinces seem to exceed the others, but Sondrio once again exhibits the lowest concentrations. Cremona (CR), Mantova (MN) and Pavia (PV) record very high amounts of $\mathrm{PM}_{2.5}$ in the air during the winter months, and in some cases, as in 2016, they reach or exceed Milan (MI) or Monza-Brianza (MB). This may be due to the triangular relationship between agricultural activities, ammonia emissions, and $\mathrm{PM}_{2.5}$. Intensive agriculture generates high levels of ammonia, which is transformed into ultrafine particulate matter, increasing concentrations. Livelli al di sopra dei limiti.
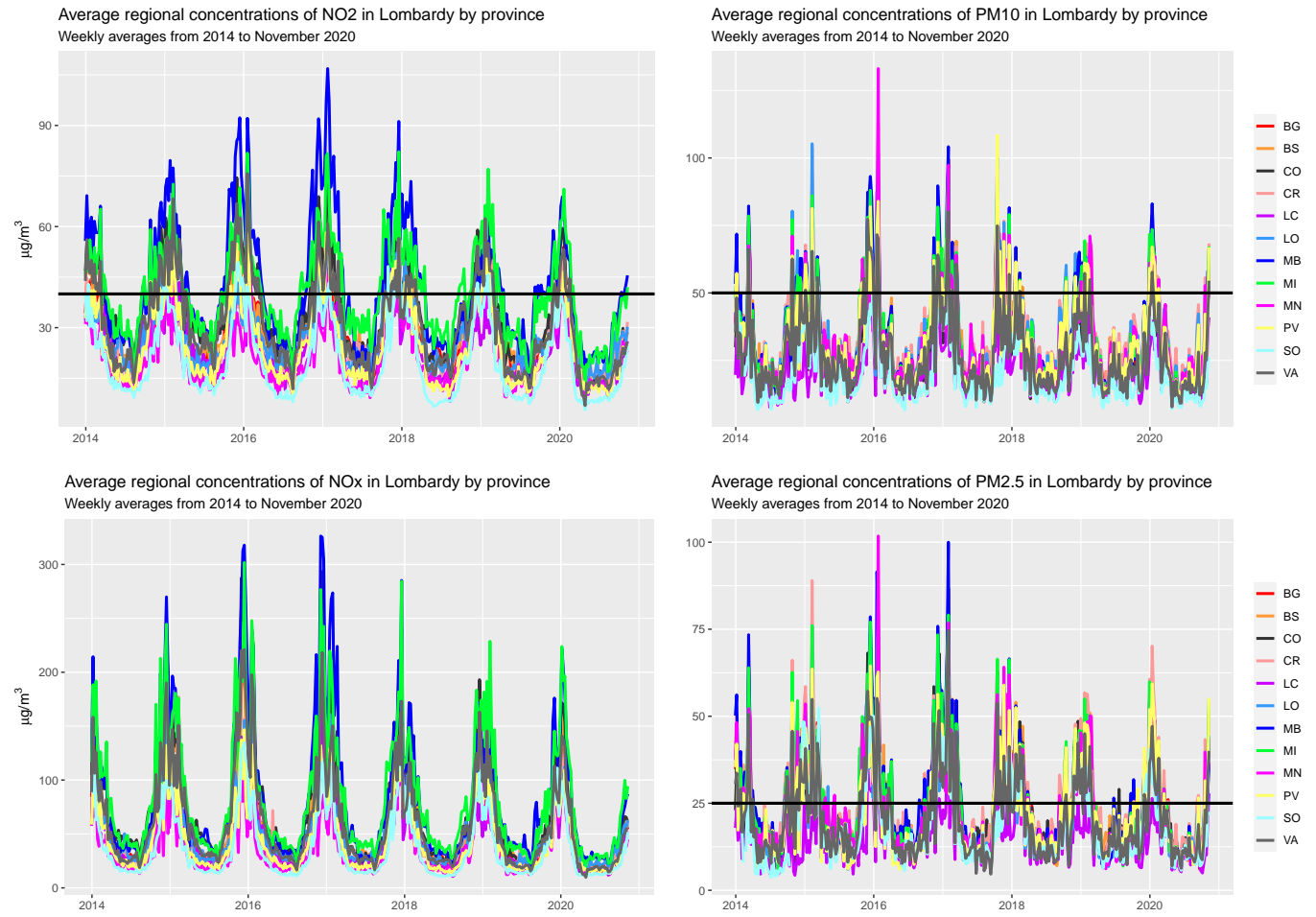

Figure 15. Average weekly concentrations of $\mathrm{NO}_{2}, \mathrm{NO}_{x}, \mathrm{PM}_{10}, \mathrm{PM}_{2.5}$ in Lombardy by province. Horizontal line for $\mathrm{NO}_{2}$ is the EU yearly average limit, while the horizontal lines for $\mathrm{PM}_{10}$ and $\mathrm{PM}_{2.5}$ are the daily EU limits. Upper left panel: average weekly concentrations of $\mathrm{NO}_{2}$ by province; lower left panel: average weekly concentrations of $\mathrm{NO}_{x}$ by province; upper right panel: average weekly concentrations of $\mathrm{PM}_{10}$ by province; lower right panel: average weekly concentrations of $\mathrm{PM}_{2.5}$ by province.

Figures 16 and 17 report the average weekly measurements of $\mathrm{NO}_{x}, \mathrm{NO}_{2}$ classified by area type and emission sources. Both figures clearly show that the observed concentrations are strongly dependent on the type of station, and thus on the area surrounding the monitoring site. This is particularly true for oxide concentrations. At first, for both total oxides and nitrogen dioxide the urban and traffic stations record values well above the other types throughout the period considered. Their spring and summer readings are 
around $25-30 \mu \mathrm{g} / \mathrm{m}^{3}$, while in the winter months they reach levels of $65-70 \mu \mathrm{g} / \mathrm{m}^{3}$ (well above the permitted legal limits). Rural stations have values permanently below $40 \mu \mathrm{g} / \mathrm{m}^{3}$. Background stations stand reasonably in the middle, because of their purpose of monitoring sites not directly adjacent to emission sources. In contrast, fine and ultrafine substances do not appear to be affected by station classification and show homogeneous concentrations. Taking as reference the EU daily limits, i.e., $50 \mu \mathrm{g} / \mathrm{m}^{3}$ for $\mathrm{PM}_{10}$ and $25 \mu \mathrm{g} / \mathrm{m}^{3}$ for $\mathrm{PM}_{2.5}$, concentrations seem out of control during winter and under control during the rest of the year. The data show that as of 2019, particulate matter has experienced large reductions compared to 2016-2018, but there is still great potential for improvement.
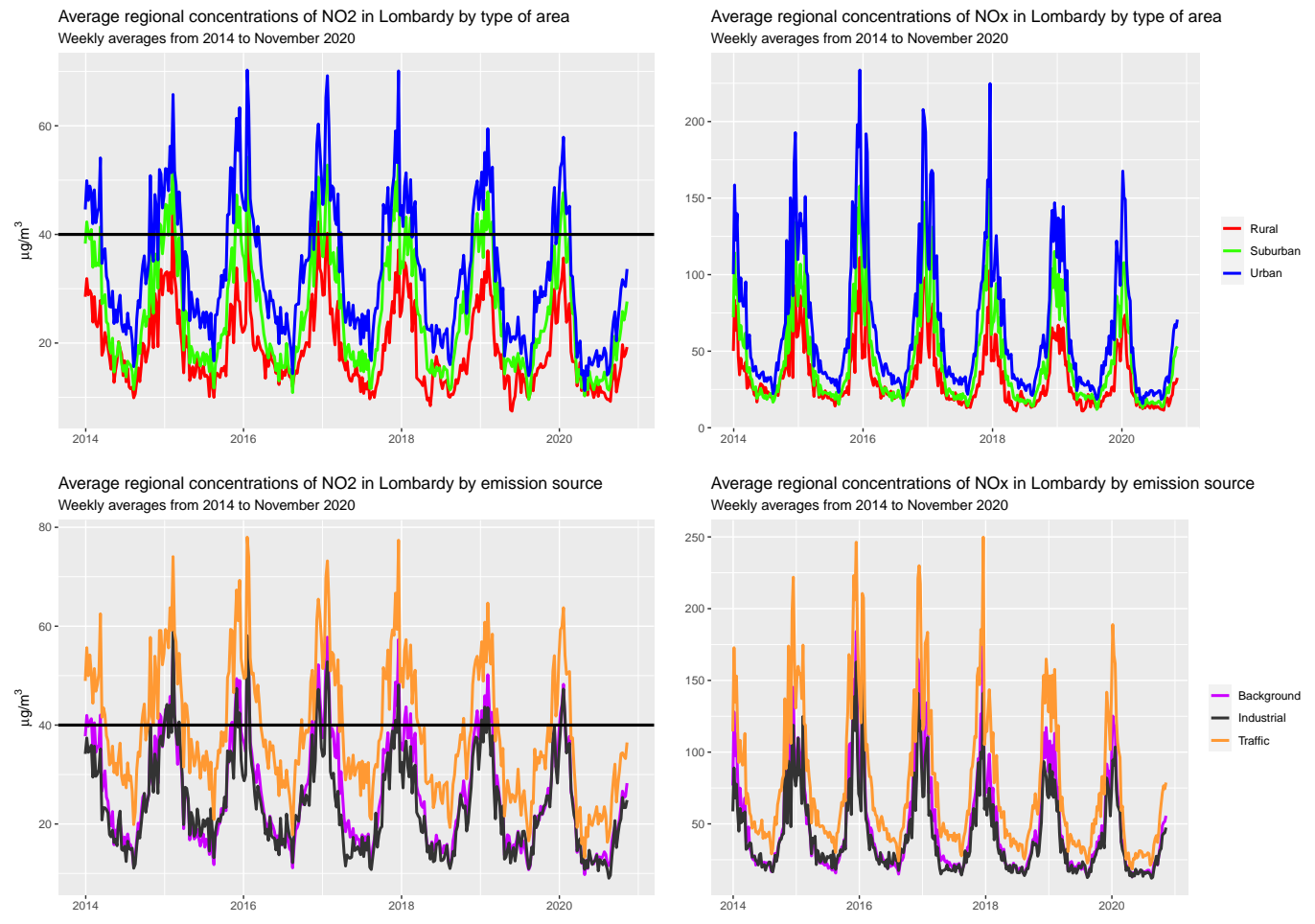

Figure 16. Average weekly concentrations of $\mathrm{NO}_{2}$ and $\mathrm{NO}_{x}$ by type of area (rural, urban or suburban) and by type of emission source (traffic, background or industrial) in Lombardy. Horizontal lines for $\mathrm{NO}_{2}$ are the EU daily average limit. Upper left panel: average weekly concentrations of $\mathrm{NO}_{2}$ by type of area; lower left panel: average weekly concentrations of $\mathrm{NO}_{2}$ by emission source; upper right panel: average weekly concentrations of $\mathrm{NO}_{x}$ by type of area; lower right panel: average weekly concentrations of $\mathrm{NO}_{x}$ by emission source.

As preliminary observational results, it is possible to state, in line with what reported by the European Environment Agency, that Lombardy suffers from concentrations well above the allowed limits for almost all pollutants considered, especially in winter periods, and needs immediate interventions on the production structure and mobility.

Lombardy is subject to a continental climate, characterized by warm and humid summers and cold winters. During anticyclonic episodes, the region experiences higher concentrations of atmospheric aerosols, persistent fog and haze [57]. Meteorology is considered a key factor in monitoring air quality data, especially because ignoring the relationship between weather and pollutants would inevitably lead to biased estimates of concentrations and even underestimates $[8,51,58]$. The Po basin, in particular the Lombardy region, enjoys an unfavorable microclimate that generates large accumulations and pockets of pollutants. The presence of the Alps to the north and the Apennine chain to the south (Figure 10) heavily inhibits wind circulation.

Using the data available from the open data of ARPA Lombardia, it is possible to obtain an intuitive insight about the meteorological situation in the region. The wind speed 
is poor and does not allow the recycling and cleaning of the air. This situation is well described in the Figure 18, which distinguishes the wind in the region.
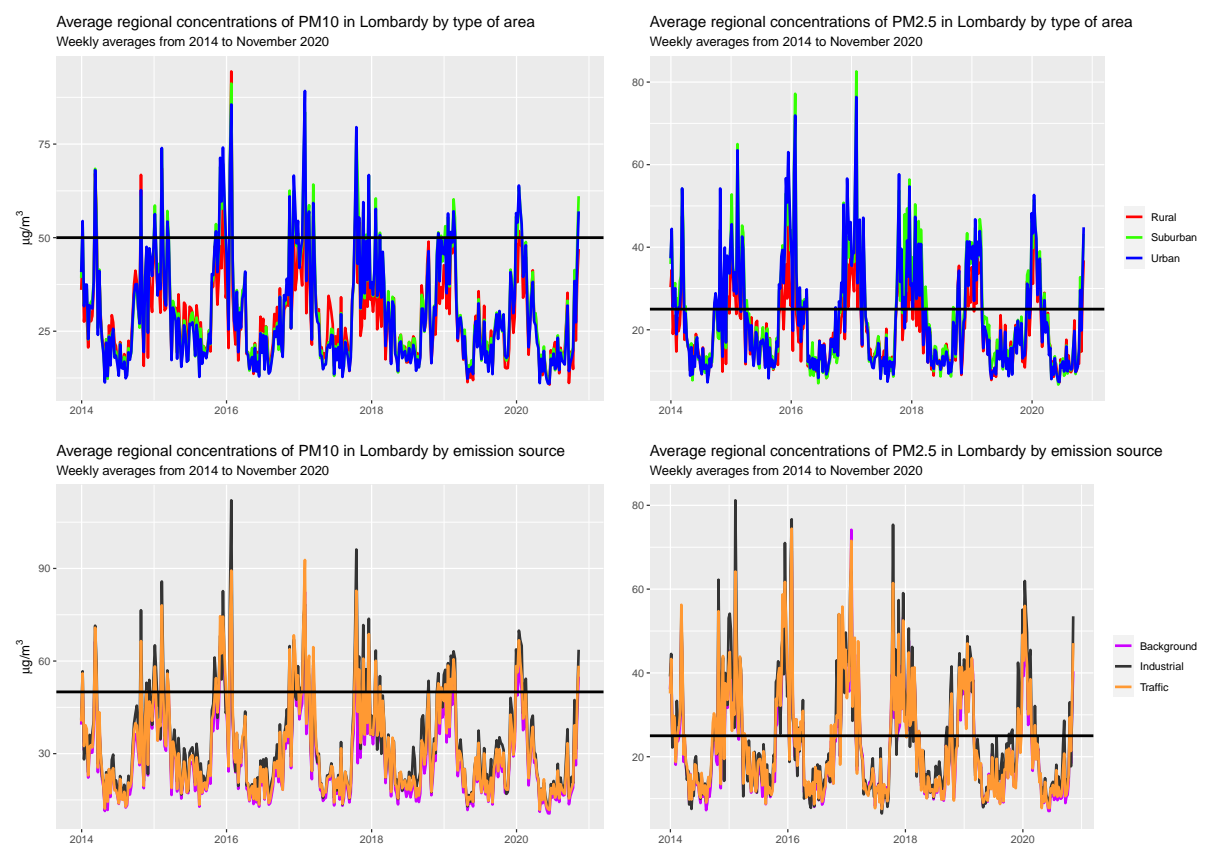

Figure 17. Average weekly concentrations of particulate matters by type of area (rural, urban or suburban) and by type of emission source (traffic, background or industrial) in Lombardy. Horizontal lines are the EU daily average limit. Upper left panel: average weekly concentrations of $\mathrm{PM}_{10}$ by type of area; lower left panel: average weekly concentrations of $\mathrm{PM}_{10}$ by emission source; upper right panel: average weekly concentrations of $\mathrm{PM}_{2.5}$ by type of area; lower right panel: average weekly concentrations of $\mathrm{PM}_{2.5}$ by emission source.
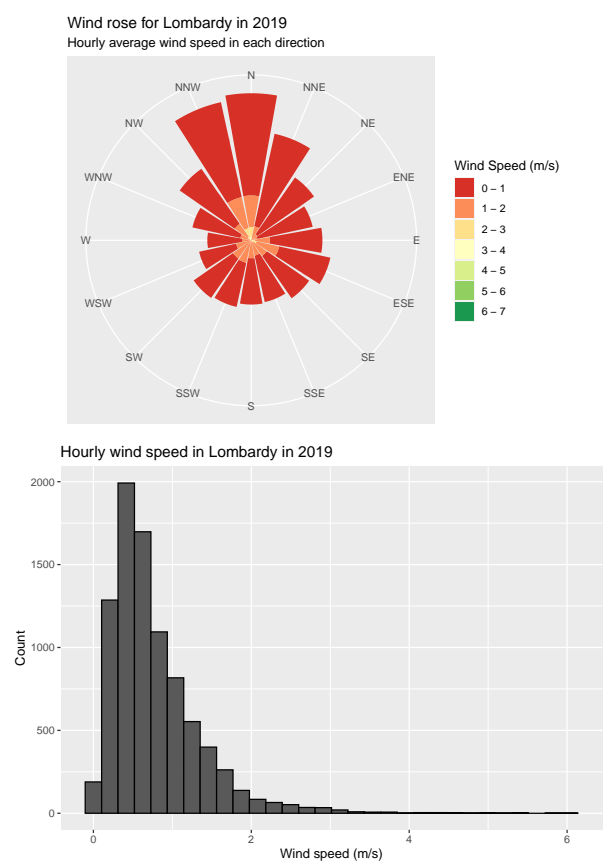

Figure 18. Main characteristics of the wind in Lombardy in 2019. Wind compass with average wind speed in each direction at regional level (upper-left panel); Wind compass with average wind speed by month (upper-right panel); histogram of the hourly wind speed (lower-left panel); histogram of the hourly wind direction (lower-right panel).
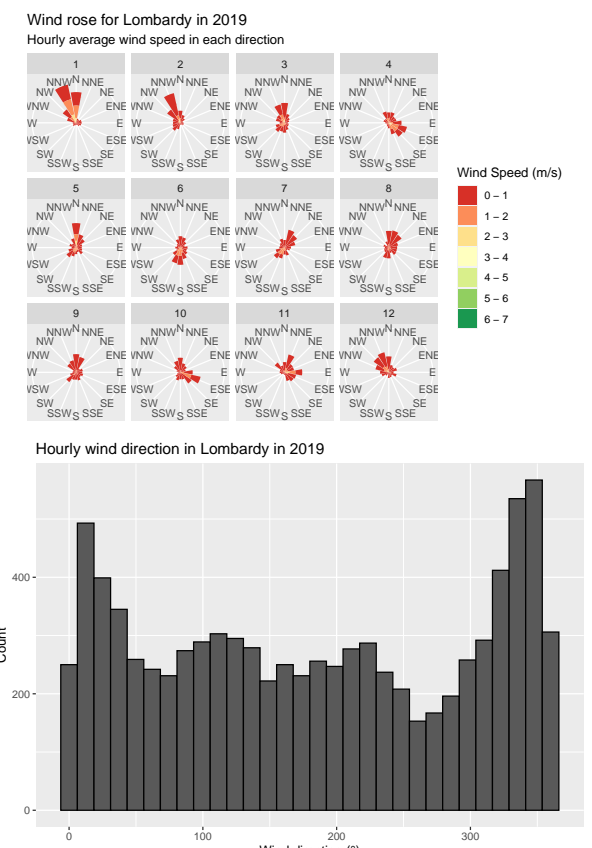

Wind direction $\left(^{\circ}\right)$ 
The average hourly wind speed registered is very low, most of the records are well below $2 \mathrm{~m} / \mathrm{s}$ and never above $7 \mathrm{~m} / \mathrm{s}$, consistently with the findings of other studies such as [59-61]. This fact is also confirmed in Figure 19, which shows the average (left panel) and maximum (right panel) wind speed measured at each monitoring location of the ARPA Lombardia network. Looking at the mean speed, the highest values are associated with stations in the Alps chain (North) or in the Appennini chain (South). However, the average value never exceeds $5 \mathrm{~m} / \mathrm{s}$. Instead, wind gusts can reach values over $75 \mathrm{~m} / \mathrm{s}$, once again in the mountainous areas. The distribution of wind direction (upper panels of Figure 18) shows that the wind blows mainly from the North (high concentration of cases around $0^{\circ}$ and $360^{\circ}$ ) with some reduced peaks from the East (values in the $80^{\circ}$ to $100^{\circ}$ range). During the year, it is possible to notice some heterogeneity between the seasons. For example, in the winter months (December-February) the main wind comes from the north and has a higher speed than the rest of the year, while between spring and summer, the wind increases from the south and east.
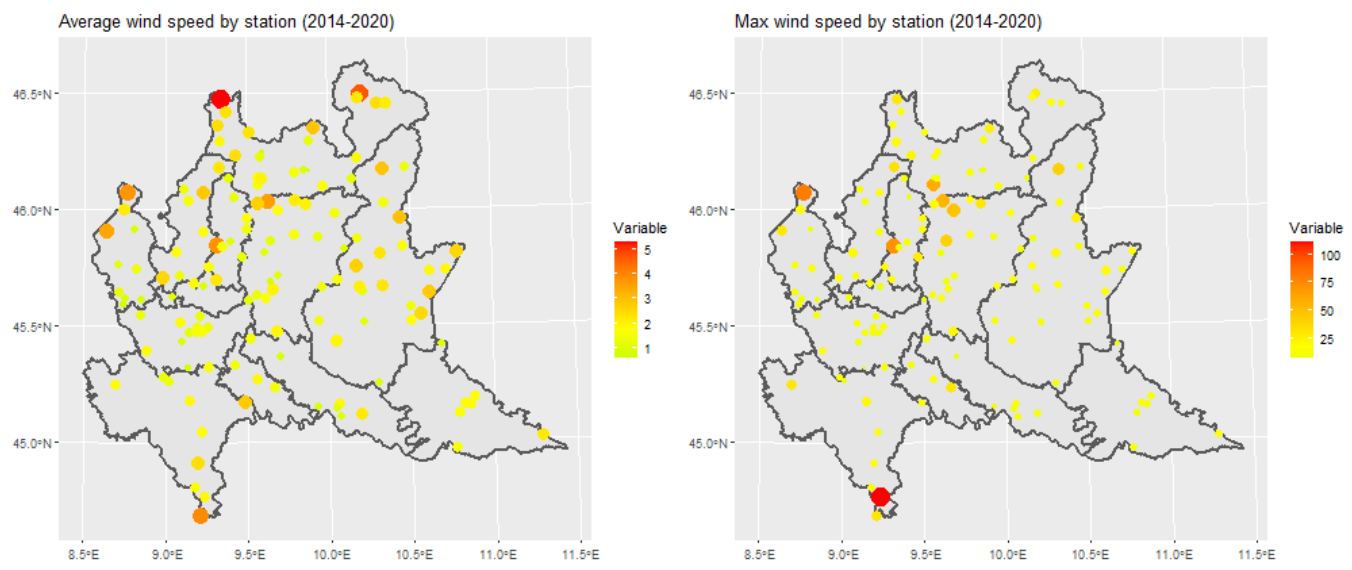

Figure 19. Average (left panel) and maximum (right panel) wind speed measured at each ARPA Lombardia monitoring site. Average and maximum values are obtained aggregating observations from 2014 to 2020.

Another relevant factor for air cleaning is the rainfall, here reported by Figure 20. Precipitation also seems to discourage air cleaning. The Lombardy region records a modest amount of water precipitation, almost always less than $5 \mathrm{~mm}$ daily total. A slight variability of rainfall is recorded during the year: in the coldest winter months (December-January), rainfall of less than $2 \mathrm{~mm}$ daily is recorded for almost the whole month, while in May, August and November, the highest rainfall is recorded. Spatial variability of rainfall is another phenomenon to consider. As discussed by [62], in Northern Italy the distribution of annual precipitation among the plain and the mountains deeply changed over time, with an increase of the precipitation at the high elevations compared to the low elevations starting in the mid-20th century and peaking in the 1980s. The latter fact is also confirmed in our data by Figure 21, which reports the average rainfall observed during May (left panel) and the average rainfall observed across the whole year (right panel) for each monitoring site of the ARPA Lombardia network. By averaging the entire period, which looks uniform over the territory, we confirm what we stated earlier, namely that the amount of rain is very low, almost systematically less than $2 \mathrm{~mm}$. If we consider the rainiest month, i.e., May, the spatial heterogeneity is emphasized: on the mountain range (North) we reach rainfall of more than $8 \mathrm{~mm}$, while in the southern plain rainfall remains very scarce. 


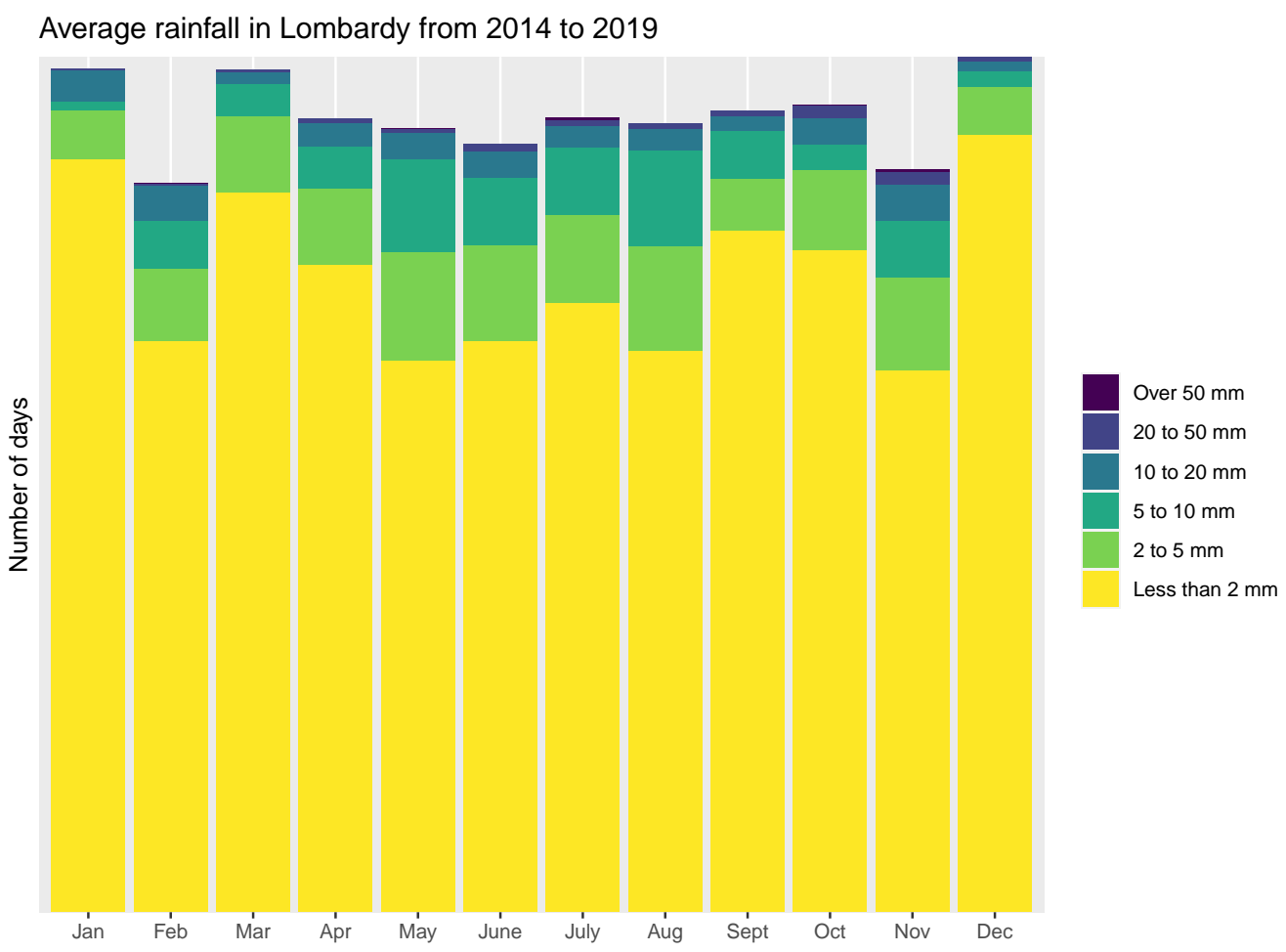

Figure 20. Number of rainy days during the month classified according to the precipitation quantity.

Average rainfall in Lombardy by station
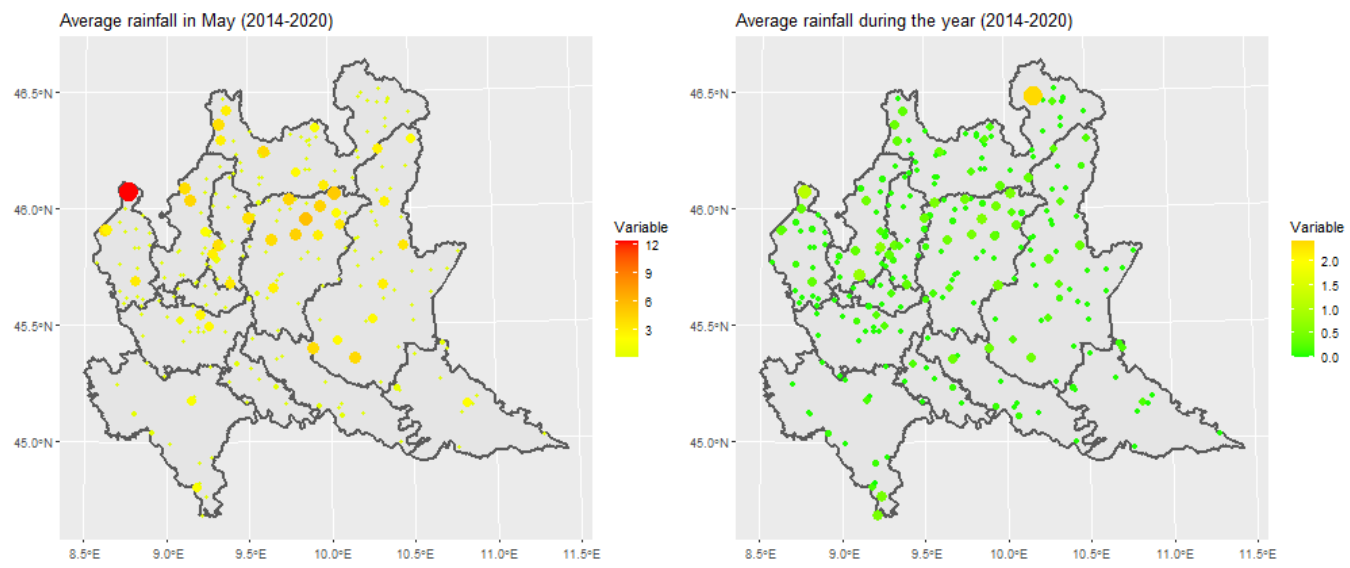

Figure 21. Average rainfall registered in May (left panel) and registered across the year (right panel) at each ARPA Lombardia monitoring site. Average values are obtained aggregating observations from 2014 to 2020

Finally, we move on to regional temperature patterns. Specifically, we report the average, minimum and maximum weekly temperatures recorded across the region from 2016 to November 2020 (Figure 22) and the average weekly temperature by province (Figure 23). 


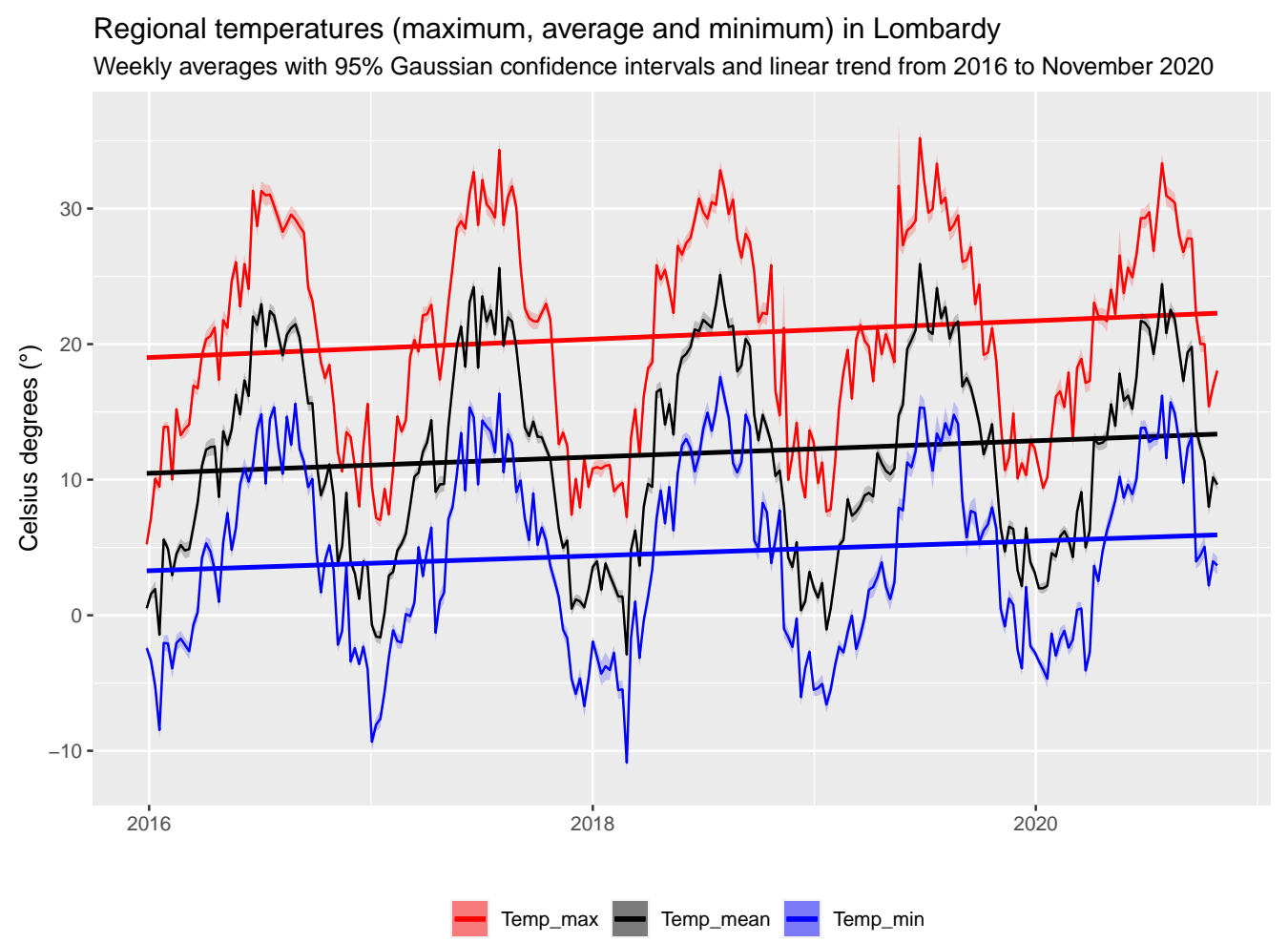

Figure 22. Average, minimum and maximum weekly temperature at regional level from 2016 to November 2020.

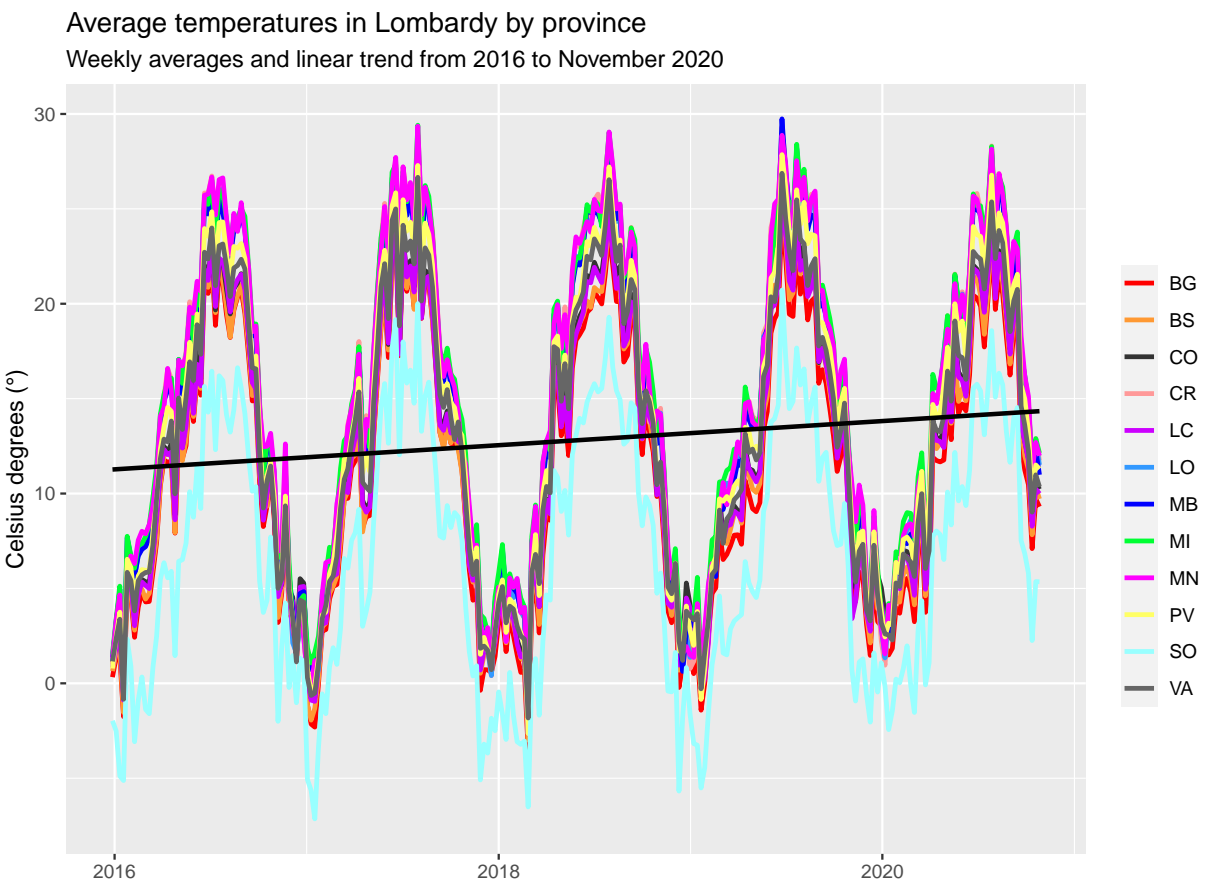

Figure 23. Average weekly temperature at provincial level from 2016 to November 2020.

The key message that both figures highlight is that in the last years, the temperature recorded in Lombardy is increasing, both the minimum and the maximum. This is evidenced by the clear increasing linear trend superimposed on the observed temperatures. In particular, the regional minimum temperature (blue line in the Figure 22) is rapidly increasing: in January 2016, the minimum temperature was around $3^{\circ}$, while at the end of 
2019, it stabilized between 5 and $6^{\circ}$ Celsius, recording the highest minimum temperature of the period under study. The observed increases in average temperature are also visible at the provincial level. All provinces recorded higher average temperatures in 2019 and 2020 than in previous years. Interestingly, the province of Sondrio (light blue line in Figure 23), located in the far north of the region and bordering Switzerland, recorded values around zero in early 2019, while during the same period in 2016 or 2017, the temperature was well below zero.

The period considered to derive the preceding evidences is too short to establish long-term connections and/or causal relationships related to climate change in the region. However, even in the short term, it is evident that something is quickly changing in the anthropogenic impact on local Lombardy quality. The decreasing trends in oxides concentrations recorded after 2016, reaching minimum levels in 2020, could be influenced by consistent improvements in citizens' vehicle fleets, with a wider use of carbon-neutral vehicles, or changes in the industrial productive system, more careful to the territory and to the control of emissions.

\section{Conclusions}

In this article, we aimed at describing the main features of the Italian environmental monitoring system linking it to the European guidelines on environmental protection and public data dissemination. Italy adopts a vertical structure in which the bodies in charge of managing the ground networks are the Regional Agencies ARPA. In fact, the Italian regions are entrusted with the important task of monitoring the atmosphere and pollution, producing reports on a periodic basis and disseminating as much information as possible to citizens and institutions. Given the international relevance of the case study, we have analyzed in detail the case of air quality in the Lombardy region (Northern Italy), economic and industrial center of the Po Valley, and the functioning of the Regional Environmental Protection Agency, namely ARPA Lombardia. The air quality recorded in Lombardy is an emblematic case study with a crucial scientific and social relevance. In spite of the efforts of the authorities to counteract the phenomenon of pollution, it is still difficult to comply with international regulations on the concentrations of air pollutants. The consequence is a continuous pressure on administrations and citizens to reduce the environmental impact of human activities.

One of the objectives we have pursued is to present the Lombardy case study and the available public data, making available to an international audience some important information on the available public data on the Lombardy environment. In particular, we have explicitly indicated and discussed the sources and tools for retrieving the data (the dashboards that ARPA and the Regione Lombardia provide) and the degree of statistical quality of the data. With reference to the quality from a statistical point of view, one of the key points of the paper is the spatial (localization) and temporal (time coverage) mapping of the terrestrial monitoring network in relation to the main pollutants monitored (particulate matter, oxides and metals).

Finally, we have arranged some simple descriptive analyses of the essential features of meteorology and air quality observed in Lombardy between 2014 and 2020 using data provided by the regional authority for environmental protection, ARPA Lombardia. The analyses presented are to be intended simply as an example of a potential use of information from the agency and should not be interpreted as an outline of long-term air quality trends in relation to regional meteorology.

The results show that in the short term, concentrations are affected by noticeable decreasing trends, but with a rather moderate time rate. This is particularly true for the concentrations of oxides $\left(\mathrm{NO}_{2}\right.$ and $\left.\mathrm{NO}_{X}\right)$ in urban and industrial areas. Atmospheric particulate matter $\left(\mathrm{PM}_{10}\right.$ and $\left.\mathrm{PM}_{2.5}\right)$ and ozone $\left(\mathrm{O}_{3}\right)$, on the other hand, show high persistence, interrupted only by the alternation of climatic seasons. The data also show that the meteorology of the region does not seem favorable for the improvement of air quality. In fact, Lombardy is characterized by low precipitation, especially in the winter months, and 
wind almost everywhere is not very intense and rarely above $7 \mathrm{~m} / \mathrm{s}$. This situation could be induced by the unfavorable geography of the area, closed to the north by the C-shaped curvature of the Alps and to the south by the Apennines, which prevents adequate air recycling and facilitates the stagnation of pollutants. We suggest that any public policy intervention aimed at improving the air quality situation in the region (see, for example, $[50,51,63,64]$ on the use of limited traffic zones as a deterrent for the use of vehicles in cities and the reduction of pollutant concentrations) should take into account this empirical evidence in the impact assessment phase.

Funding: This research received no external funding.

Institutional Review Board Statement: Not applicable.

Informed Consent Statement: Not applicable.

Data Availability Statement: Data and codes can be requested by email to P.M. (paolo.maranzano@unibg.it).

Acknowledgments: The author thanks his colleague Andrea Algieri of ARPA Lombardia for supporting the research during the past months.

Conflicts of Interest: The authors declare no conflict of interest.

Sample Availability: Data used for the analysis can be retrieved: 1) from the ARPA Lombardia dashboard; 2) using the $R$ package ARPALData (version 1.2.2 available on CRAN); 3) contacting the author at paolo.maranzano@unimib.it.

\author{
Abbreviations \\ The following abbreviations are used in this manuscript: \\ ARPA Agenzia Regionale Protezione Ambiente (Regional Environmental Protection Agency) \\ INEMAR Inventario Emissioni Aria (Air Emission Inventory) \\ PM Particulate Matters \\ $\mathrm{PM}_{10} \quad$ with a diameter of $10 \mu \mathrm{m}$ or less \\ $\mathrm{PM}_{2.5} \quad$ with a diameter of $2.5 \mu \mathrm{m}$ or less \\ $\mathrm{NO}_{2} \quad$ Nitrogen Dioxide \\ $\mathrm{NO}_{X} \quad$ Total Nitrogen Oxides
}

\title{
References
}

1. Global Environment Outlook. Global Environment Outlook-GEO-6: Healthy Planet, Healthy People; Cambridge University Press: Cambridge, UK, 2019. [CrossRef]

2. Gulia, S.; Nagendra, S.S.; Khare, M.; Khanna, I. Urban air quality management-A review. Atmos. Pollut. Res. 2015, 6, 286-304. [CrossRef]

3. Sivertsen, B. Monitoring air quality, objectives and design. Chem. Ind. Chem. Eng. Q. 2008, 14, 167-171. [CrossRef]

4. Kobori, H.; Dickinson, J.L.; Washitani, I.; Sakurai, R.; Amano, T.; Komatsu, N.; Kitamura, W.; Takagawa, S.; Koyama, K.; Ogawara, T. Citizen science: A new approach to advance ecology, education, and conservation. Ecol. Res. 2016, 31, 1-19. [CrossRef]

5. Domenico, G. ESD Operators: Roles and Duties for the Environmental Monitoring Activities of ARPA Puglia. Earth 2021, 10, 180-188.

6. Bottazzi, M.; Scipione, G.; Marras, G.F.; Trotta, G.; D’Antonio, M.; Chiavarini, B.; Caroli, C.; Montanari, M.; Bassini, S.; Gascón, E. The Italian open data meteorological portal: MISTRAL. Meteorol. Appl. 2021, 28, e2004. [CrossRef]

7. Gardiol, D.; Cellino, A.; Di Martino, M. PRISMA, Italian network for meteors and atmospheric studies. In Proceedings of the IMC, Egmond, The Netherlands. 2-5 June 2016. Available online: http://hdl.handle.net/20.500.12386/24394 (accessed on 1 February 2022)

8. Fassò, A.; Maranzano, P.; Otto, P. Spatiotemporal variable selection and air quality impact assessment of COVID-19 lockdown. Spat. Stat. 2021, 100549. [CrossRef]

9. Zhong, L.; Louie, P.K.; Zheng, J.; Wai, K.M.; Ho, J.W.; Yuan, Z.; Lau, A.K.; Yue, D.; Zhou, Y. The Pearl River Delta regional air quality monitoring network-regional collaborative efforts on joint air quality management. Aerosol Air Qual. Res. 2013, 13, 1582-1597. [CrossRef]

10. Zheng, J.; Zhong, L.; Wang, T.; Louie, P.K.K.; Li, Z. Ground-level ozone in the Pearl River Delta region: Analysis of data from a recently established regional air quality monitoring network. Atmos. Environ. 2010, 44, 814-823. [CrossRef]

11. Cameletti, M. The Effect of Corona Virus Lockdown on Air Pollution: Evidence from the City of Brescia in Lombardia Region (Italy). Atmos. Environ. 2020, 239, 117794. [CrossRef] 
12. Joly, M.; Peuch, V.H. Objective classification of air quality monitoring sites over Europe. Atmos. Environ. 2012, 47, 111-123. [CrossRef]

13. Ignaccolo, R.; Mateu, J.; Giraldo, R. Kriging with external drift for functional data for air quality monitoring. Stoch. Environ. Res. Risk Assess. 2014, 28, 1171-1186. [CrossRef]

14. Bo, M.; Charvolin-Volta, P.; Clerico, M.; Nguyen, C.V.; Pognant, F.; Soulhac, L.; Salizzoni, P. Urban air quality and meteorology on opposite sides of the Alps: The Lyon and Torino case studies. Urban Clim. 2020, 34, 100698. [CrossRef]

15. Masiol, M.; Squizzato, S.; Formenton, G.; Harrison, R.M.; Agostinelli, C. Air quality across a European hotspot: Spatial gradients, seasonality, diurnal cycles and trends in the Veneto region, NE Italy. Sci. Total Environ. 2017, 576, 210-224. [CrossRef]

16. Cassoni, F.; Bocchi, C.; Martino, A.; Pinto, G.; Fontana, F.; Buschini, A. The Salmonella mutagenicity of urban airborne particulate matter (PM2.5) from eight sites of the Emilia-Romagna regional monitoring network (Italy). Sci. Total Environ. 2004, 324, 79-90. [CrossRef]

17. Mocerino, L.; Murena, F.; Quaranta, F.; Toscano, D. A methodology for the design of an effective air quality monitoring network in port areas. Sci. Rep. 2020, 10, 300. [CrossRef]

18. Mofarrah, A.; Husain, T. A holistic approach for optimal design of air quality monitoring network expansion in an urban area. Atmos. Environ. 2010, 44, 432-440. [CrossRef]

19. Benis, K.Z.; Fatehifar, E.; Shafiei, S.; Nahr, F.K.; Purfarhadi, Y. Design of a sensitive air quality monitoring network using an integrated optimization approach. Stoch. Environ. Res. Risk Assess. 2016, 30, 779-793. [CrossRef]

20. Wang, C.; Zhao, L.; Sun, W.; Xue, J.; Xie, Y. Identifying redundant monitoring stations in an air quality monitoring network. Atmos. Environ. 2018, 190, 256-268. [CrossRef]

21. Völgyesi, P.; Nádas, A.; Koutsoukos, X.; Lédeczi, Á. Air quality monitoring with sensormap. In Proceedings of the 2008 International Conference on Information Processing in Sensor Networks (ipsn 2008), St. Louis, MO, USA , 22-24 April 2008; pp. 529-530.

22. Postolache, O.A.; Pereira, J.D.; Girao, P.S. Smart sensors network for air quality monitoring applications. IEEE Trans. Instrum. Meas. 2009, 58, 3253-3262. [CrossRef]

23. Morawska, L.; Thai, P.K.; Liu, X.; Asumadu-Sakyi, A.; Ayoko, G.; Bartonova, A.; Bedini, A.; Chai, F.; Christensen, B.; Dunbabin, M.; et al. Applications of low-cost sensing technologies for air quality monitoring and exposure assessment: How far have they gone? Environ. Int. 2018, 116, 286-299. [CrossRef]

24. Castell, N.; Dauge, F.R.; Schneider, P.; Vogt, M.; Lerner, U.; Fishbain, B.; Broday, D.; Bartonova, A. Can commercial low-cost sensor platforms contribute to air quality monitoring and exposure estimates? Environ. Int. 2017, 99, 293-302. [CrossRef] [PubMed]

25. Williams, D.E.; Henshaw, G.S.; Bart, M.; Laing, G.; Wagner, J.; Naisbitt, S.; Salmond, J.A. Validation of low-cost ozone measurement instruments suitable for use in an air-quality monitoring network. Meas. Sci. Technol. 2013, 24, 065803. [CrossRef]

26. Harkat, M.F.; Mourot, G.; Ragot, J. An improved PCA scheme for sensor FDI: Application to an air quality monitoring network. J. Process Control 2006, 16, 625-634. [CrossRef]

27. Harkat, M.F.; Mansouri, M.; Nounou, M.; Nounou, H. Enhanced data validation strategy of air quality monitoring network. Environ. Res. 2018, 160, 183-194. [CrossRef]

28. European Parliament and Council of the European Union. Directive 2004/107/EC of the European Parliament and of the Council of 15 December 2004 Relating to Arsenic, Cadmium, Mercury, Nickel and Polycyclic Aromatic Hydrocarbons in Ambient Air. 2004. Available online: https://www.eumonitor.eu/9353000/1/j9vvik7m1c3gyxp/vitgbgig0qzr (accessed on 20 January 2022).

29. European Parliament and Council of the European Union. Directive 2008/50/EC of the European Parliament and of the Council of 21 May 2008 on Ambient Air Quality and Cleaner Air for Europe. 2008. Available online: https://eur-lex.europa.eu/legalcontent/en/ALL/?uri=CELEX:32008L0050 (accessed on 20 January 2022).

30. WHO. Air Quality Guidelines for Europe; WHO Regional Publications, European Series; World Health Organization: Geneva, Switzerland, 2000; Volume 91, ISSN 0378-2255.

31. WHO. Air Quality Guidelines: Global Update 2005: Particulate Matter, Ozone, Nitrogen Dioxide, and Sulfur Dioxide; World Health Organization: Geneva, Switzerland, 2006.

32. European Parliament and Council of the European Union. Decision No 1600/2002/EC of the European Parliament and of the Council of 22 July 2002 Laying down the Sixth Community Environment Action Programme. 2002. Available online: https:/ / op.europa.eu/en/publication-detail/-/publication/4263f8fc-f705-4176-b54e-d8f63700c1a0/language-en (accessed on 20 January 2022).

33. European Parliament and Council of the European Union. Decision No 1386/2013/EU of the European Parliament and of the Council of 20 November 2013 on a General Union Environment Action Programme to 2020 'Living well, within the limits of our planet' Text with EEA relevance. Off. J. Eur. Union 2013, 354, 171-200.

34. European Environmental Agency. Europe's Urban Air Quality-Re-Assessing Implementation Challenges in Cities; EEA Report No 24/2018; European Environmental Agency: Copenhagen, Denmark, 2018. [CrossRef]

35. European Environmental Agency. Air Quality in Europe-2019 Report; Report; European Environmental Agency: Copenhagen, Denmark, 2019.

36. van den Elshout, S.; Léger, K.; Nussio, F. Comparing urban air quality in Europe in real time: A review of existing air quality indices and the proposal of a common alternative. Environ. Int. 2008, 34, 720-726. [CrossRef] 
37. Italian Government Legge 132/2016, Sistema Nazionale a Rete per la Protezione Dell'ambiente. $2016 . \quad$ Available online: https:/ / www.isprambiente.gov.it/it/sistema-nazionale-protezione-ambiente (accessed on 1 February 2022).

38. European Environmental Agency. EMEP/EEA Air Pollutant Emission Inventory Guidebook 2019; EEA Report No 13/2019; European Environmental Agency: Copenhagen, Denmark, 2019. [CrossRef]

39. R Core Team. R: A Language and Environment for Statistical Computing; R Foundation for Statistical Computing: Vienna, Austria, 2020.

40. Caserini, S.; Fraccaroli, A.; Monguzzi, A.M.; Moretti, M.; Giudici, A.; Angelino, E.; Fossati, G.; Gurrieri, G. A detailed Emission Inventory for air quality planning at local scale: The Lombardy (Italy) experience. In Proceedings of the 13th Emission Inventory Conference of the US Environmental Protection Agency, Clearwater, FL, USA, 8-10 June 2004.

41. Regional Statistical Yearbook. Lombardia Regional Statistical Yearbook 2017/2018; Report; ASR Lombardia: Milan, Italy, 2017. Available online: https:/ / www.asr-lombardia.it/asrlomb/sites/www.asr-lombardia.it.asrlomb/files/pubblicazioni/42686\% 20Province_inglese_web.pdf (accessed on 20 January 2022)

42. Regional Statistical Yearbook. Regional Statistical Yearbook of Lombardia in Europe 2017/2018; Report; ASR Lombardia: Milan, Italy, 2017. Available online: https://www.asr-lombardia.it/asrlomb/sites/www.asr-lombardia.it.asrlomb/files/pubblicazioni/4268 5\%20Lombardia\%20in\%20Europe_ENG_web.pdf (accessed on 20 January 2022)

43. Raffaelli, K.; Deserti, M.; Stortini, M.; Amorati, R.; Vasconi, M.; Giovannini, G. Improving Air Quality in the Po Valley, Italy: Some Results by the LIFE-IP-PREPAIR Project. Atmosphere 2020, 11, 429. [CrossRef]

44. INEMAR ARPA Lombardia Settore Aria. INEMAR Emission Inventory 2017: Emission in Lombardy Region; Final Data-Public Revision; INEMAR ARPA Lombardia Settore Aria: Milan, Italy, 2020.

45. Hristov, A.N. Contribution of ammonia emitted from livestock to atmospheric fine particulate matter $\left(\mathrm{PM}_{2.5}\right)$ in the United States J. Dairy Sci. 2011, 94, 3130-3136. [CrossRef]

46. Baccini, M.; Biggeri, A.; Grillo, P.; Consonni, D.; Bertazzi, P.A. Health impact assessment of fine particle pollution at the regional level. Am. J. Epidemiol. 2011, 174, 1396-1405. [CrossRef]

47. Baccini, M.; Grisotto, L.; Catelan, D.; Consonni, D.; Bertazzi, P.A.; Biggeri, A. Commuting-adjusted short-term health impact assessment of airborne fine particles with uncertainty quantification via Monte Carlo simulation. Environ. Health Perspect. 2015, 123, 27-33. [CrossRef]

48. Carugno, M.; Consonni, D.; Randi, G.; Catelan, D.; Grisotto, L.; Bertazzi, P.A.; Biggeri, A.; Baccini, M. Air pollution exposure, cause-specific deaths and hospitalizations in a highly polluted Italian region. Environ. Res. 2016, 147, 415-424. [CrossRef]

49. Carugno, M.; Consonni, D.; Bertazzi, P.A.; Biggeri, A.; Baccini, M. Temporal trends of PM10 and its impact on mortality in Lombardy, Italy. Environ. Pollut. 2017, 227, 280-286. [CrossRef]

50. Fassò, A. Statistical assessment of air quality interventions. Stoch. Environ. Res. Risk Assess. 2013, 27, 1651-1660. [CrossRef]

51. Maranzano, P.; Fassò, A.; Pelagatti, M.; Mudelsee, M. Statistical Modeling of the Early-Stage Impact of a New Traffic Policy in Milan, Italy. Int. J. Environ. Res. Public Health 2020, 17, 1088. [CrossRef]

52. Lombardia, A. Analisi Preliminare Della Qualità Dell'aria in Lombardia Durante l'emergenza COVID-19; Report; ARPA Lombardia: Milan, Italy, 2020.

53. Lovarelli, D.; Conti, C.; Finzi, A.; Bacenetti, J.; Guarino, M. Describing the trend of ammonia, particulate matter and nitrogen oxides: The role of livestock activities in northern Italy during Covid-19 quarantine. Environ. Res. 2020, 191, 110048. [CrossRef]

54. Lovarelli, D.; Fugazza, D.; Costantini, M.; Conti, C.; Diolaiuti, G.; Guarino, M. Comparison of ammonia air concentration before and during the spread of COVID-19 in Lombardy (Italy) using ground-based and satellite data. Atmos. Environ. 2021, 259 , 118534. [CrossRef]

55. Rossi, R.; Ceccato, R.; Gastaldi, M. Effect of Road Traffic on Air Pollution. Experimental Evidence from COVID-19 Lockdown. Sustainability 2020, 12, 8984. [CrossRef]

56. Collivignarelli, M.C.; Abbà, A.; Bertanza, G.; Pedrazzani, R.; Ricciardi, P.; Carnevale Miino, M. Lockdown for CoViD-2019 in Milan: What are the effects on air quality? Sci. Total Environ. 2020, 732, 139280. [CrossRef] [PubMed]

57. Lolli, S.; Chen, Y.C.; Wang, S.H.; Vivone, G. Impact of Meteorology and Air Pollution on COVID-19 Pandemic Transmission in Lombardy Region, Northern Italy. 2012. Available online: https://protocolexchange.researchsquare.com/article/pex-1045/v1 (accessed on 20 January 2022).

58. Pernigotti, D.; Georgieva, E.; Thunis, P.; Bessagnet, B. Impact of meteorology on air quality modeling over the Po valley in northern Italy. Atmos. Environ. 2012, 51, 303-310. [CrossRef]

59. Ceylan, Z. Insights into the relationship between weather parameters and COVID-19 outbreak in Lombardy, Italy. Int. J. Healthc. Manag. 2021, 14, 255-263. [CrossRef]

60. Fazzini, M.; Baresi, C.; Bisci, C.; Bna, C.; Cecili, A.; Giuliacci, A.; Illuminati, S.; Pregliasco, F.; Miccadei, E. Preliminary analysis of relationships between covid19 and climate, morphology, and urbanization in the lombardy region (Northern Italy). Int. J. Environ. Res. Public Health 2020, 17, 6955. [CrossRef]

61. Stufano, A.; Lisco, S.; Bartolomeo, N.; Marsico, A.; Lucchese, G.; Jahantigh, H.; Soleo, L.; Moretti, M.; Trerotoli, P.; De Palma, G.; et al. COVID19 outbreak in Lombardy, Italy: An analysis on the short-term relationship between air pollution, climatic factors and the susceptibility to SARS-CoV-2 infection. Environ. Res. 2021, 198, 111197. [CrossRef]

62. Napoli, A.; Crespi, A.; Ragone, F.; Maugeri, M.; Pasquero, C. Variability of orographic enhancement of precipitation in the Alpine region. Sci. Rep. 2019, 9, 13352. [CrossRef] 
63. Qadir, R.; Abbaszade, G.; Schnelle-Kreis, J.; Chow, J.; Zimmermann, R. Concentrations and source contributions of particulate organic matter before and after implementation of a low emission zone in Munich, Germany. Environ. Pollut. 2013, 175, 158-167. [CrossRef]

64. Percoco, M. The effect of road pricing on traffic composition: Evidence from a natural experiment in Milan, Italy. Transp. Policy 2014, 31, 55-60. [CrossRef] 